\title{
Perioperative morbidity of different operative approaches in early cervical carcinoma: a systematic review and meta-analysis comparing minimally invasive versus open radical hysterectomy
}

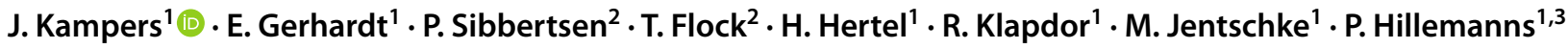

Received: 11 June 2021 / Accepted: 9 September 2021 / Published online: 8 October 2021

(c) The Author(s) 2021

\begin{abstract}
Purpose Radical hysterectomy and pelvic lymphadenectomy is the standard treatment for early cervical cancer. Studies have shown superior oncological outcome for open versus minimal invasive surgery, but peri- and postoperative complication rates were shown vice versa. This meta-analysis evaluates the peri- and postoperative morbidities and complications of robotic and laparoscopic radical hysterectomy compared to open surgery.

Methods Embase and Ovid-Medline databases were systematically searched in June 2020 for studies comparing robotic, laparoscopic and open radical hysterectomy. There was no limitation in publication year. Inclusion criteria were set analogue to the LACC trial. Subgroup analyses were performed regarding the operative technique, the study design and the date of publication for the endpoints intra- and postoperative morbidity, estimated blood loss, hospital stay and operation time.

Results 27 studies fulfilled the inclusion criteria. Five prospective, randomized-control trials were included. Meta-analysis showed no significant difference between robotic radical hysterectomy (RH) and laparoscopic hysterectomy (LH) concerning intra- and perioperative complications. Operation time was longer in both RH (mean difference 44.79 min [95\% CI 38.16; 51.42]), and LH (mean difference $20.96 \mathrm{~min}$; [95\% CI - 1.30; 43.22]) than in open hysterectomy (AH) but did not lead to a rise of intra- and postoperative complications. Intraoperative morbidity was lower in LH than in AH (RR 0.90 [0.80; 1.02]) as well as in $\mathrm{RH}$ compared to $\mathrm{AH}(0.54$ [0.33; 0.88]). Intraoperative morbidity showed no difference between $\mathrm{LH}$ and $\mathrm{RH}$ (RR 1.29 [0.23; 7.29]). Postoperative morbidity was not different in any approach. Estimated blood loss was lower in both LH (mean difference - 114.34 [-122.97; - 105.71]) and RH (mean difference - 287.14 [-392.99; - 181.28]) compared to $\mathrm{AH}$, respectively. Duration of hospital stay was shorter for LH (mean difference $-3.06[-3.28 ;-2.83]$ ) and RH (mean difference $-3.77[-5.10 ;-2.44])$ compared to $\mathrm{AH}$.

Conclusion Minimally invasive radical hysterectomy appears to be associated with reduced intraoperative morbidity and blood loss and improved reconvalescence after surgery. Besides oncological and surgical factors these results should be considered when counseling patients for radical hysterectomy and underscore the need for new randomized trials.
\end{abstract}

Keywords Early cervical cancer $\cdot$ Radical hysterectomy $\cdot$ Minimally-invasive $\cdot$ Laparoscopy $\cdot$ Robot-assisted $\cdot$ Postoperative morbidity

J. Kampers

kampers.johanna@mh-hannover.de

P. Hillemanns

hillemanns.peter@mh-hannover.de

1 Department of Gynecology and Obstetrics, Hannover Medical School, Carl-Neuberg-Str.1, 30625 Hannover, Germany

2 Faculty of Economics and Management, Leibniz University Hannover, Hannover, Germany

3 Comprehensive Cancer Center Niedersachsen (CCC-N), Hannover, Germany

\section{Introduction}

Surgical therapy of early cervical cancer (FIGO Sta$\operatorname{dium} \leq \mathrm{IIA}$ ) is primarily recommended by national and international guidelines [1]. Miscellaneous surgical approaches were established to perform radical hysterectomy and lymphadenectomy. According to mostly retrospective studies abdominal radical hysterectomy appears to be associated with a higher rate of morbidities such as bladder dysfunction, longer hospital stay or postoperative infection compared to laparoscopic radical hysterectomy (LH) [2-4]. 
Systematic reviews showed the superiority of laparoscopic hysterectomy regarding inoperative blood loss, hospital stay and postoperative complications over the abdominal approach [5-7].

In addition, these reviews reported similar oncological outcomes between $\mathrm{LH}$ and $\mathrm{AH}$ which led to the wide implementation of LH as a standard approach in early cervical cancer [6].

The publication of the LACC (Laparoscopic Approach to Cervical Cancer) trial in 2018, the first large multicenter randomized controlled trial comparing $\mathrm{AH}$ with LH approaches in early cervical cancer, led to a drastic change of recommendations for operative treatment [8]. The LACC trial showed a reduced overall- (OS) and disease-free survival (DFS) in the minimally invasive therapy group, compared to open radical hysterectomy. A reduction of perioperative morbidity in the minimally invasive therapy group was not shown in this prospective trial, either.

These results contradicted previous results of systematic reviews comparing laparoscopic and robotic $(\mathrm{RH})$ with open surgical approaches [6]. Robot-assisted operations, which have been introduced into the gynecologic oncologic operative field a decade ago [9], were included in the minimally invasive results in this study. In previous meta-analyses [10-12] a non-inferiority of robot-assisted approaches regarding perioperative complication rates compared to $\mathrm{LH}$ or AH was shown.

This meta-analysis was performed to evaluate the morbidities and clinical outcomes of cervical cancer patients treated by $\mathrm{RH}, \mathrm{LH}$ or $\mathrm{AH}$.

\section{Materials and methods}

The methods for this study were specified a priori based on the recommendations in the Preferred Reporting Items for Systematic Reviews and Meta-Analyses (PRISMA) statement [13].

\section{Search strategy}

A systematic database research for studies comparing $\mathrm{RH}$ with $\mathrm{LH}$ or $\mathrm{AH}$ for the treatment of early cervical cancer via Ovid-Medline and EMBASE without restriction of publication year was performed. Search terms combined MESH-terms (uterine neoplasms) or Emtree headings and the related terms "cervical cancer", "uterine cancer", "cervical neoplasm", as well as "laparoscopic surgery", "hysterectomy", "Wertheim operation", "Robotics," and "roboticassisted surgery".

\section{Study selection}

Study selection was done independently by JK and EG. In case of conflicting opinions PH decided about inclusion or exclusion. The inclusion criteria were adapted to the inclusion criteria of the LACC trial [8] and specified 1. studies that included patients with early cervical cancer FIGO IA1, IA2, IB1, IB2, IIA1, 2. comparative studies between $\mathrm{RH}$ or $\mathrm{OH}$ or $\mathrm{LH}, 3$. studies that reported at least one outcome of interest, and 4. published original, peerreviewed articles. Only studies with complete publication of all results were considered. Non-original studies, animal or preclinical trials, abstract-only publications, reports in a language other than English or German and duplicates were excluded. All reasons for exclusion are mentioned in the Preferred Reporting Items for Systematic Reviews and Meta-Analyses flowchart (Fig. 1). One study already presented at ESGO congress prior to the systematic research was added by hand search upon publication.

The algorithms used for primary search as well as the full list of search results can be found in the supplementary items. If possible, the authors of studies that were only published as congress abstracts were tried to be contacted via email and asked to provide their data.

\section{Data extraction and quality assessment}

The updated Cochrane risk of bias tool 2 (RoB 2) was used to assess the scientific quality of the included studies [14] (Fig. 2). The quality assessments were performed by two independent researchers (JK and EG). Disagreements were resolved by consensus of all authors.

Two reviewers independently extracted the safety and effectiveness indexes into a pre-specified data extraction form and double checked them.

\section{Statistical analysis}

Inter-study heterogeneity was assessed using the maximum likelihood estimator with calculation of $\tau 2$ and its corresponding $p$ value [15]. This $p$ value indicates the probability that deviation from inter-study homogeneity can be explained by chance with a lower $p$ value implying significant heterogeneity. The $95 \%$ confidence intervals (CI) were used as the summary variables for continuous outcomes and the risk rate (RR) and 95\% CI for dichotomous variables.

Statistical analysis was conducted by fixed-effect models in the absence of significant heterogeneity and randomeffect models in the presence of significant heterogeneity. Analysis was by intention to treat. Subgroup analyses 


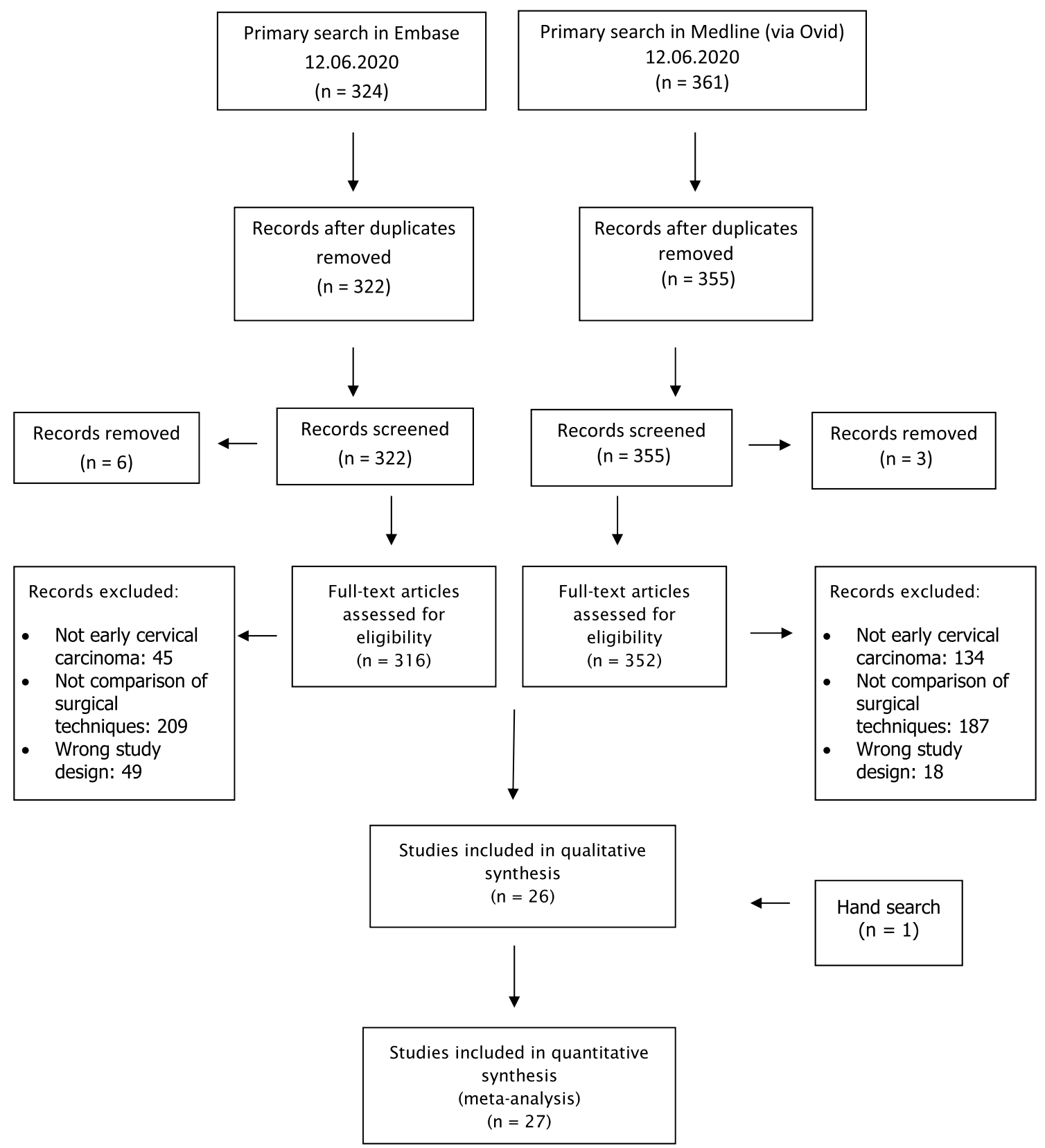

Fig. 1 PRISMA flowchart

were prespecified according to the study design and the year of publication (before or after the LACC study data publication).

\section{Results}

685 studies met the inclusion criteria and were assessed for eligibility. After removing records with no full text, wrong study designs (e.g. reviews) wrong patient selection (e.g. chemotherapy before operation) and duplicates, 27 suitable comparative studies were included into final analysis. Table 1 shows the characteristics of the 27 studies.

The studies were performed in the USA, Asia, Europe and Brazil. The publication years ranged from 2007-2020. 15.713 patients with operative treatment of early cervical carcinoma were included. 8.021 patients were treated with open surgery and 479 by robotic surgery, respectively. 7.213 patients received laparoscopic surgery. Five prospective, randomized-control trials were included. The design of 22 studies design was retrospective. One study [16] compared all three operative approaches. 19 studies compared LH to 


\section{Studies with intention-to-treat}

\begin{tabular}{|c|c|c|c|c|c|c|c|c|c|c|c|}
\hline $\begin{array}{l}\cong \\
\frac{0}{3} \\
\frac{0}{5}\end{array}$ &  &  & 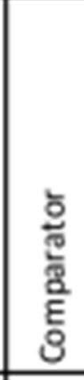 & 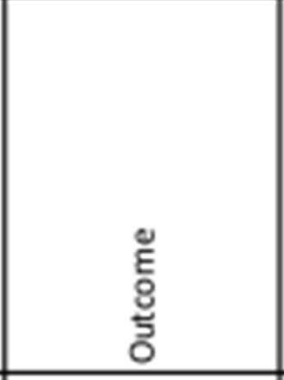 & $\begin{array}{l}\frac{\tilde{c}}{\mathrm{c}} \\
\frac{\mathrm{at}}{\mathrm{s}} \\
\frac{1}{3}\end{array}$ & 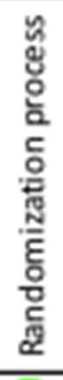 &  &  & 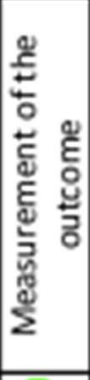 & 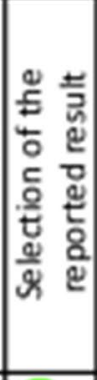 & 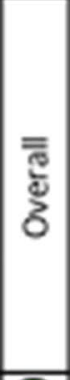 \\
\hline A1 & Campos et al. & $\mathrm{LH}$ & $\mathrm{AH}$ & PM/Pain & 1 & + & + & + & + & + & \\
\hline$A 2$ & Frumovitz et al. & $\underline{H}(+\mathrm{RH})$ & AH & QUality of Life & 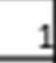 & + & + & + & + & $?$ & \\
\hline A3 & Naik et al. & $\mathrm{RH}$ & $\mathrm{LH}_{\mathrm{H}}$ & PM/POM & 2 & + & + & + & $?$ & + & \\
\hline A4 & Obermair et al. & $\mathrm{LH}(+\mathrm{RH})$ & $\mathrm{AH}$ & PM/POM & 1 & + & + & + & + & + & \\
\hline AS & Ramirez et al. & $\mathrm{LH}(+\mathrm{RH})$ & АH & DFS/OS & 2 & 1 & + & + & + & + & \\
\hline$A 6$ & Corrado et al. & $\mathrm{RH}$ & $-\mathrm{H}$ & $\mathrm{PM} / \mathrm{POM}$ & 1 & 2 & + & + & + & - & \\
\hline A7 & Diver et al. & $\mathrm{H}(+\mathrm{RH})$ & $\mathrm{AH}$ & OS/RR/PM & 1 & & + & + & $?$ & $?$ & \\
\hline 48 & Doo et al. & $\mathrm{RH}$ & АH & DS/DFS/RR/PM & 1 & & + & + & $?$ & - & \\
\hline A9 & Dos Reis et al. & $\mathrm{L}(+\mathrm{RH})$ & AH & PM/POM & 1 & & + & + & $?$ & - & \\
\hline A10 & Kim S et al & $\mathrm{H}$ & $\mathrm{AH}$ & DS/DFS/RR & 1 & & + & + & - & - & \\
\hline A11 & KIM J et al. & $\mathrm{LH}$ & AH & $\mathrm{DS} / \mathrm{PM}$ & 1 & & + & + & $?$ & $?$ & \\
\hline A12 & Kong et al. & $\mathrm{H}$ & $\mathrm{AH}$ & DFS/PM & 1 & & + & + & $?$ & - & \\
\hline A13 & Laterza et al. & $\underline{\mathrm{H}}$ & $\mathrm{AH}$ & PM/RR & 1 & & + & + & - & $?$ & \\
\hline A14 & Li et al. & $\mathrm{H}$ & АH & OS/RR/PM & 1 & & $\theta$ & + & $?$ & $?$ & \\
\hline A15 & Malzoni et al. & $\mathrm{LH}$ & $\mathrm{AH}$ & PM/RR & & & + & + & - & $?$ & \\
\hline A16 & Melamed et al. & $\mathrm{H}(+\mathrm{RH})$ & $\mathrm{AH}$ & os & 1 & & + & + & $?$ & $?$ & \\
\hline A17 & Medivil et al. & $\mathrm{LH} / \mathrm{RH}$ & АH & OS/DFS/PM & 1 & & + & + & + & $?$ & \\
\hline A18 & Nam JH et al. & $\mathrm{LH}$ & AH & OS/DFS/PM/POM & 1 & & + & + & $?$ & $?$ & \\
\hline A19 & Nam $\boxminus$ et al. & $\mathrm{RH}$ & $\mathrm{AH}$ & RR/PM/POM & $=$ & & + & + & $?$ & $?$ & \\
\hline A.20 & paik et al. & $\mathrm{LH}$ & AH & OS/DFS/RR & - & & + & + & $?$ & $?$ & \\
\hline A21 & Park et al. & $\mathrm{LH}$ & $\mathrm{AH}$ & OS/DFS/RR/PM & $\pi$ & & + & + & $?$ & $?$ & \\
\hline A.22 & Sert et al. & $\mathrm{RH}$ & $\mathrm{LH}$ & $\mathrm{PM} / \mathrm{POM}$ & 1 & & + & + & $?$ & $?$ & \\
\hline A23 & sert et al. & $\mathrm{RH}$ & $\mathrm{AH}$ & OS/RR/PM/POM & 1 & & + & + & $?$ & $?$ & \\
\hline A.24 & Tinelli et al. & $\underline{L H}$ & $\mathrm{AH}$ & RR/PM/POM & 1 & & + & + & $?$ & - & \\
\hline A25 & Vizielli et al. & $\mathrm{RH}$ & $-\mathrm{H}$ & PM/POM & 1 & & + & + & $\theta$ & $?$ & \\
\hline A.26 & Xiao et al. & $\mathrm{LH}$ & $\mathrm{AH}$ & $\mathrm{QOL}$ & 1 & - & + & + & $?$ & $?$ & \\
\hline A.27 & Chiva et al. & $\mathrm{LH}$ & $\mathrm{AH}$ & DS/DFS & 1 & $\theta$ & + & + & $?$ & $(-)$ & \\
\hline
\end{tabular}

Fig. 2 RoB 





$\mathrm{AH}$, of which seven compared LH including RH to AH. Four studies compared $\mathrm{LH}$ to RH and three RH to $\mathrm{AH}$.

The statistical assessment revealed a large overall risk of bias since most of the included studies were neither randomized nor prospective. All included studies were assessed regarding potential conflicts of interest. In all studies the ICMJE uniform disclosure form was completed.

Subgroups were created concerning the endpoints examined (estimated blood loss (EBL), mean hospital stay (HS), operation time (OT), intraoperative morbidity (IM), postoperative morbidity (POM), the study design (randomized controlled trials (RCT)/retrospective), and the date of publication (before/after the LACC trial). Survival rates including overall and disease-free survival were published by our research group in 2021 [17].

\section{Estimated blood loss (EBL)}

The EBL (in milliliters) was lower in the LH group (mean $311.5 \mathrm{ml}$ ) than in the AH group (mean $462.27 \mathrm{ml}$; mean difference (MD) - 114.34 [-122.97; - 105.71]) (Fig. 3). The LH group of retrospective studies presented with lower EBL in the LH group (MD - 241.47 [-369.16; - 113.79]), whereas the RCT (MD - 262.00 [-555.94; 32.94]) showed no difference between the two groups (Fig. 4). There were no post-LACC studies but only pre-LACC studies that showed a lower blood loss for LH (Fig. 5).

LH versus RH (mean $140.98 \mathrm{ml}$ ) showed mixed results. Due to high heterogeneity, the random effects model was applied and revealed no significant difference between the two groups (MD 30.89 [-52.69; 114.46]) (Fig. 6).
The blood loss in RH was significantly lower than in $\mathrm{AH}$ (MD - 287.14 [-392.99; - 181.28]) (Fig. 7).

Subgroups of study design and date of publications in the LH versus $\mathrm{RH}$ and $\mathrm{RH}$ versus $\mathrm{AH}$ groups did not provide different results due to the lack of studies in either one of the groups.

\section{Mean hospital stay (HS)}

The duration of HS (in days) of patients in the LH group (mean 7.98 days) was significantly lower than in the $\mathrm{AH}$ group (mean 12.02 days; MD - $3.06[-3.28 ;-2.83]$ ) (Fig. 8). In the RCT and retrospective and pre-LACC groups, HS was significantly lower in the LH group than in the AH group, respectively (Figs. 9, 10). None of the post-LACC studies, however, examined the HS.

The LH versus RH groups (mean 4.58 days) showed mixed results. Due to high heterogeneity the random-effects model was used and showed no significant difference in HS (MD 1.07 [0.66; 1.48]) (Fig. 11).

In comparison to $\mathrm{AH}, \mathrm{RH}$ was associated with a shorter hospital stay (MD - 3.77 [-5.10; - 2.44]) (Fig. 12).

Subgroup analysis for study design and date of publications in the $\mathrm{LH}$ versus $\mathrm{RH}$ and $\mathrm{RH}$ versus $\mathrm{AH}$ groups could not be assessed due to the lack of studies in either one of the groups.

\section{Operation time (OT)}

Due to high heterogeneity, the random effects model was used in the LH versus AH analysis. LH (mean $267.37 \mathrm{~min}$ )

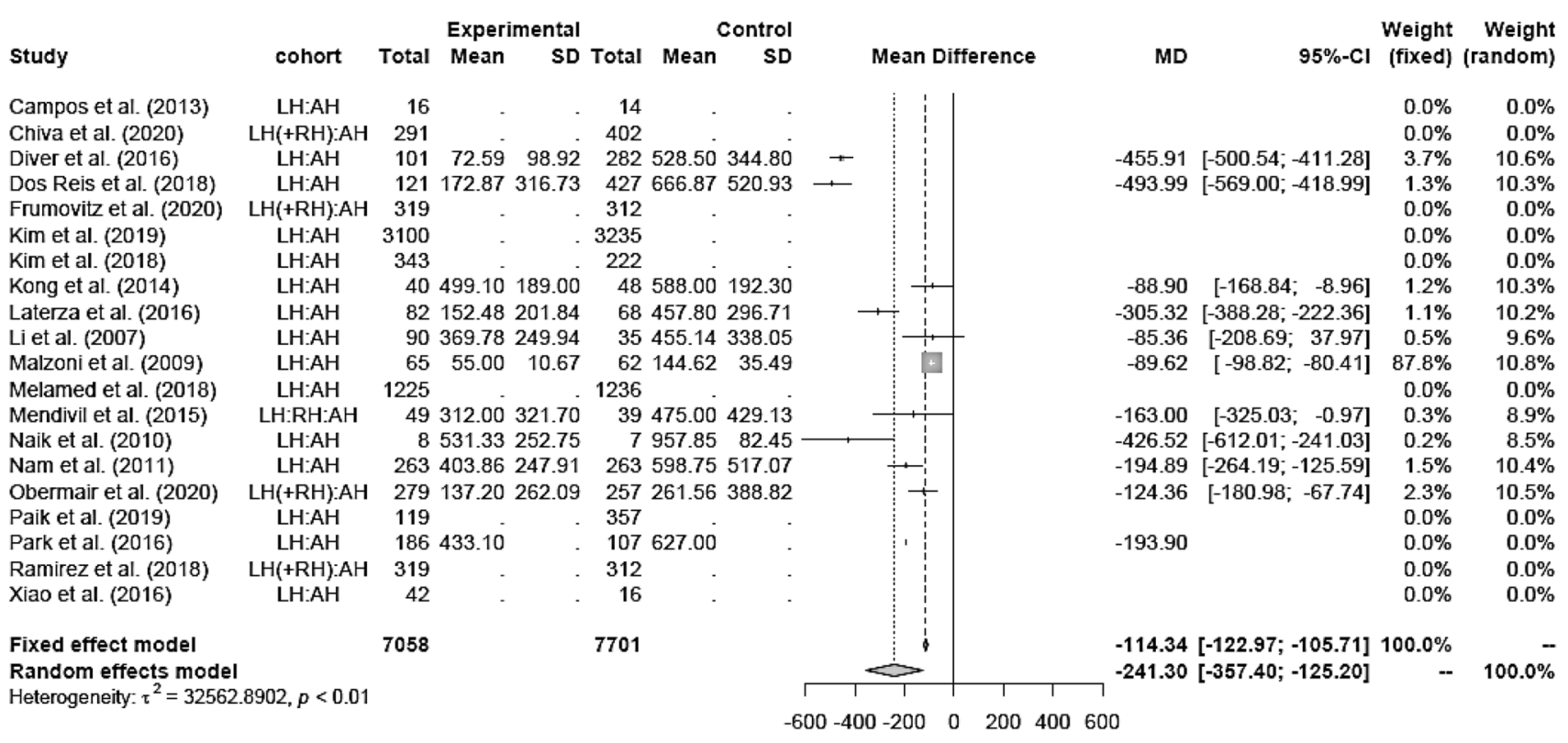

Fig. 3 Estimated blood loss LH versus AH 
Subgroup

\section{RCT}

Campos et al. (2013)

Frumovitz et al. (2020)

Naik et al. (2010)

Obermair et al. (2020)

Ramirez et al. (2018)

Random effects model

$\chi_{1}^{2}=9.32(p<0.01)$

retrospective

Chiva et al. (2020)

Diver et al. (2016)

Dos Reis et al. (2018)

Kim et al. (2019)

Kim et al. (2018)

Kong et al. (2014)

Laterza et al. (2016)

Li et al. (2007)

Malzoni et al. (2009)

Melamed et al. (2018)

Mendivil et al. (2015)

Nam et al. (2011)

Paik et al. (2019)

Park et al. (2016)

Xiao et al. (2016)

Random effects model

$\chi_{7}^{2}=377.61(p<0.01)$

Fixed effects (plural) model

$\chi_{1}^{2}=0.02(p=0.88)$

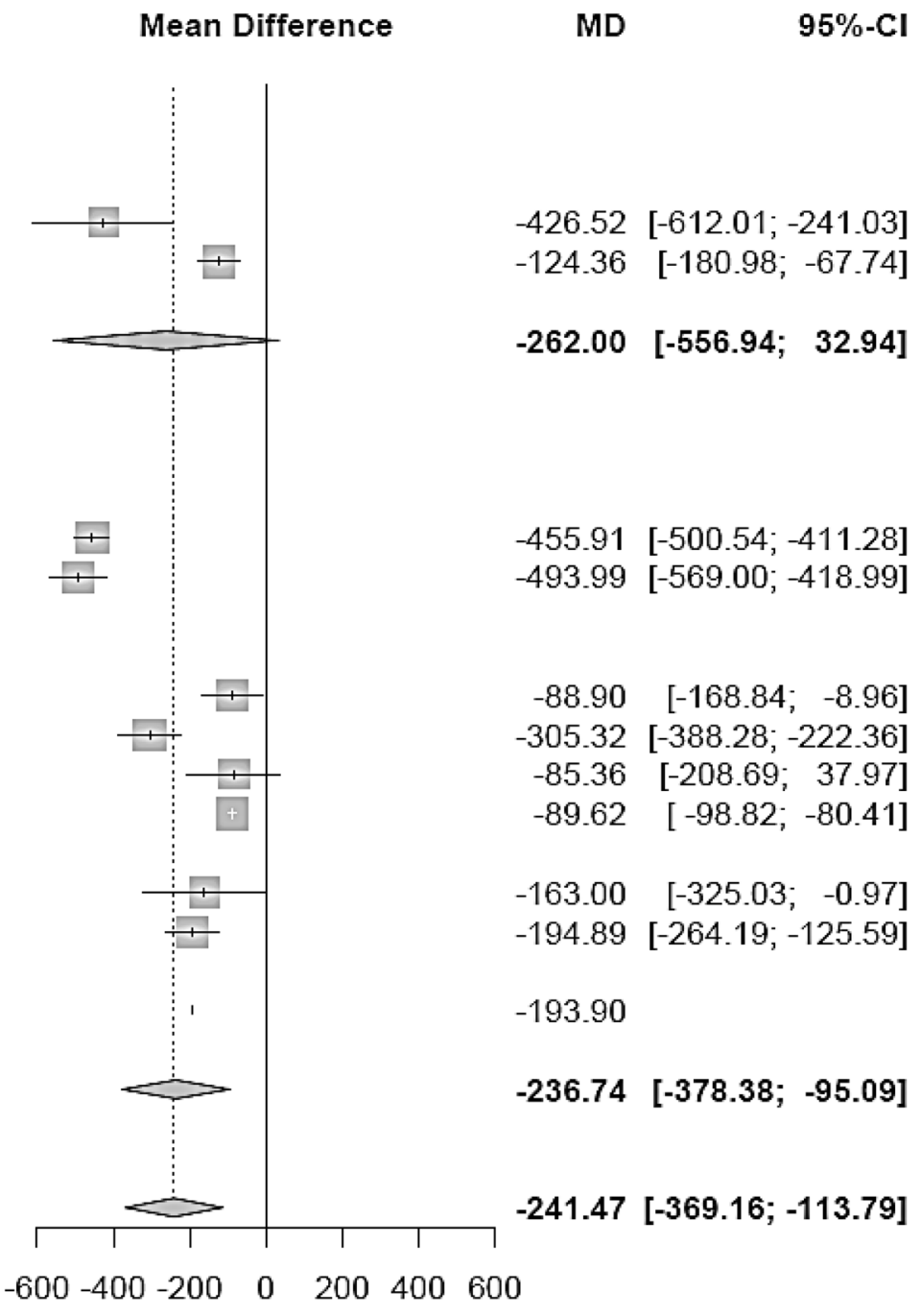

Fig. 4 Estimated blood loss LH vs AH (study design)

showed a non-significantly longer OT (in minutes) than AH (mean 213.89 min; MD 20.96 [- 1.30; 43.22]) (Fig. 13). Similar results were found in the RCT and retrospective subgroups, respectively (Figs. 14, 15).

Random effects analysis was also used comparing LH and RH (mean $250.70 \mathrm{~min}$ ). The result showed no difference in OT between both groups (Fig. 16).

OT was significantly longer in RH than in AH (MD 44.79 [38.16; 51.42]) (Fig. 17).

Subgroup analysis for study design and date of publications in the $\mathrm{LH}$ versus $\mathrm{RH}$ and $\mathrm{RH}$ versus $\mathrm{AH}$ groups could not be assessed due to the lack of studies in either one of the groups.

\section{Intraoperative morbidity (IM)}

Intraoperative morbidity included vascular, bladder, urethral and nerve injury, as well as transformation to open surgery.
There was no difference in IM in LH versus AH studies (RR $0.9095 \%$ CI [0.80; 1.02]) (Fig. 18) overall and in the RCT group, respectively. The retrospective subgroup showed a lower IM in LH (RR 0.85; [0.74; 0.97]) (Fig. 19). There were no post LACC studies evaluating IM.

LH versus RH showed no difference as well (Fig. 20). RH showed lower IM compared to AH (RR 0.54 [0.33; 0.88]) (Fig. 21).

Subgroup analysis for study design and date of publications in the $\mathrm{LH}$ versus $\mathrm{RH}$ and $\mathrm{RH}$ versus $\mathrm{AH}$ group could not be assessed due to the lack of studies in either one of the groups.

\section{Postoperative morbidity (PM)}

Postoperative morbidity included infections, abscess formation, urinary dysfunctions and incontinence as well as thrombosis and fistula. Due to high heterogeneity, the 
Subgroup

LACC

Frumovitz et al. (2020)

Obermair et al. (2020)

Ramirez et al. (2018)

Random effects model

not applicable

post LACC

Chiva et al. (2020)

Kim et al. (2018)

Paik et al. (2019)

Random effects model

not applicable

pre LACC

Campos et al. (2013)

Diver et al. (2016)

Dos Reis et al. (2018)

Kim et al. (2019)

Kong et al. (2014)

Laterza et al. (2016)

Li et al. (2007)

Malzoni et al. (2009)

Melamed et al. (2018)

Mendivil et al. (2015)

Naik et al. (2010)

Nam et al. (2011)

Park et al. (2016)

Xiao et al. (2016)

Random effects model

$\chi_{8}^{2}=388.53(p<0.01)$

Fixed effects (plural) model

$\chi_{1}^{2}=3.07(p=0.08)$
Mean Difference

MD

$95 \%-\mathrm{Cl}$

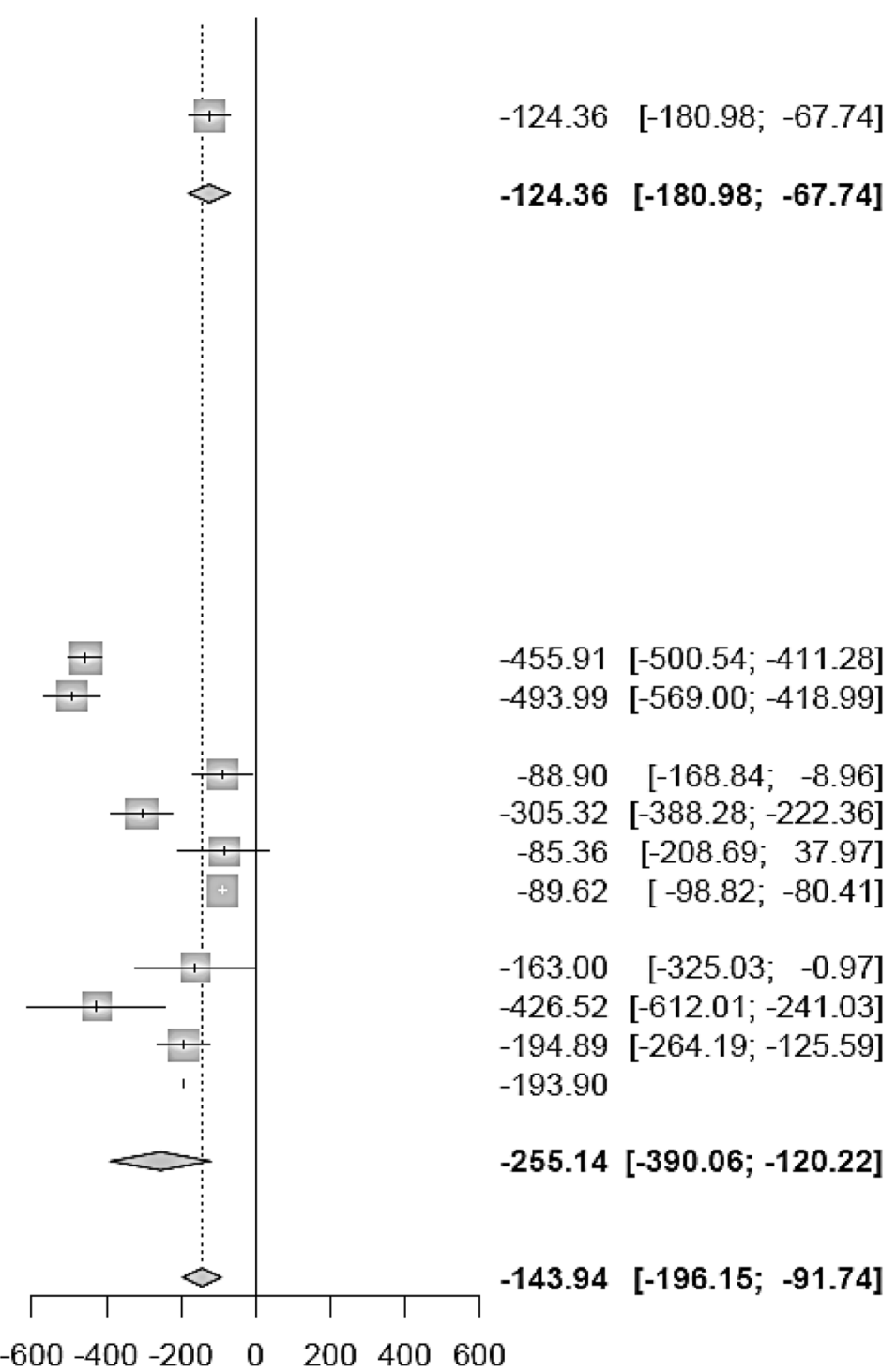

Fig. 5 Estimated blood loss LH vs AH (date of publication)

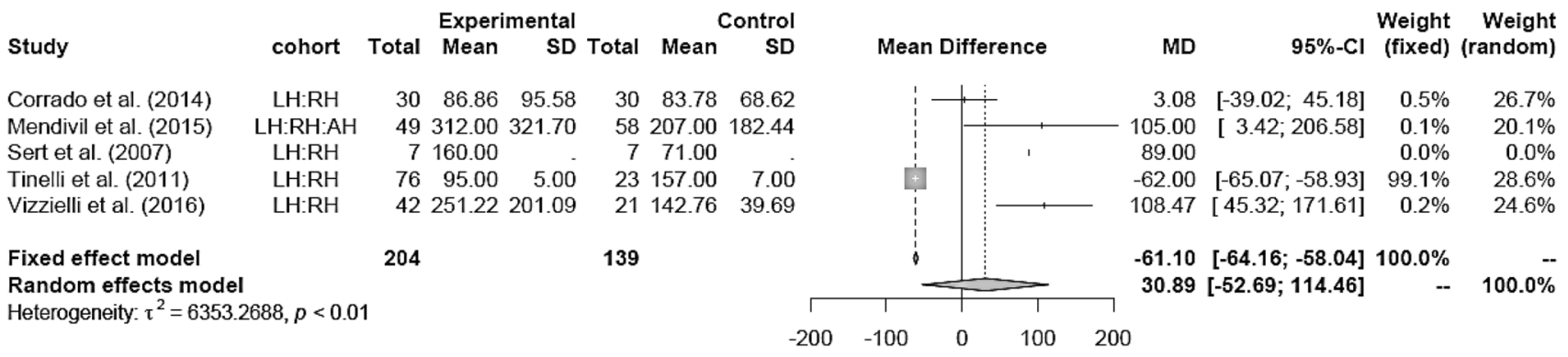

Fig. 6 Estimated blood loss LH vs RH 


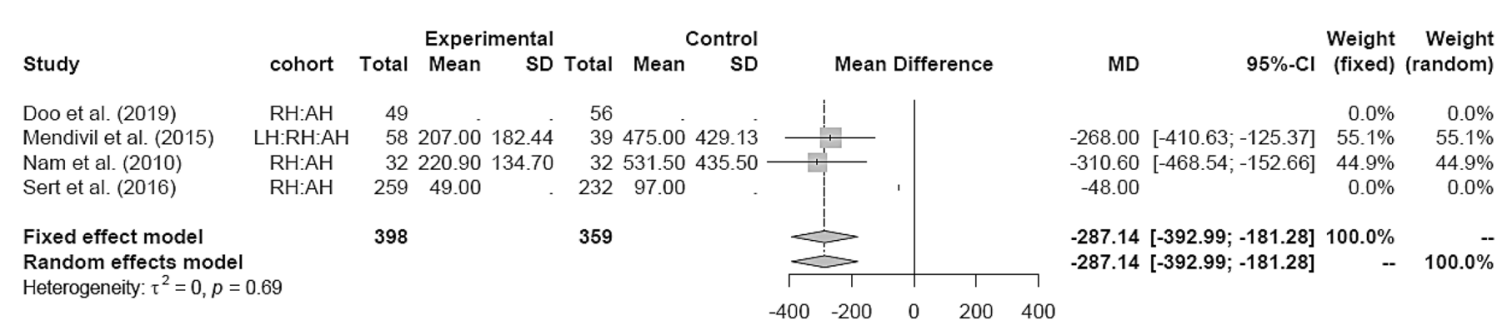

Fig. 7 Estimated blood loss RH vs AH

\begin{tabular}{|c|c|c|c|c|c|c|c|c|c|c|c|c|c|}
\hline \multirow[b]{2}{*}{ Study } & \multirow[b]{2}{*}{ cohort } & \multicolumn{3}{|c|}{ Experimental } & \multicolumn{3}{|c|}{ Control } & \multirow{2}{*}{\multicolumn{2}{|c|}{ Mean Difference }} & \multirow[b]{2}{*}{ MD } & \multirow[b]{2}{*}{$95 \%-\mathrm{Cl}$} & Weight & \multirow{2}{*}{$\begin{array}{r}\text { Weight } \\
\text { (random) }\end{array}$} \\
\hline & & Total & Mean & SD & Total & Mean & SD & & & & & (fixed) & \\
\hline Campos et al. (2013) & LH:AH & 16 & . &  & 14 & & - & & & & & $0.0 \%$ & $0.0 \%$ \\
\hline Chiva et al. (2020) & $\mathrm{LH}(+\mathrm{RH}): \mathrm{AH}$ & 291 & & & 402 & & - & & & & & $0.0 \%$ & $0.0 \%$ \\
\hline Diver et al. (2016) & $\mathrm{LH}: \mathrm{AH}$ & 101 & 1.90 & 2.60 & 282 & 4.90 & 5.30 & & & -3.00 & {$[-3.80 ;-2.20]$} & $7.8 \%$ & $11.2 \%$ \\
\hline Dos Reis et al. (2018) & $\mathrm{LH}: \mathrm{AH}$ & 121 & 2.35 & 1.75 & 427 & 6.29 & 4.03 & $\mp$ & & -3.94 & {$[-4.43 ;-3.45]$} & $20.5 \%$ & $12.2 \%$ \\
\hline Frumovitz et al. (2020) & $\mathrm{LH}(+\mathrm{RH}): \mathrm{AH}$ & 319 & . & . & 312 & . & - & & & & & $0.0 \%$ & $0.0 \%$ \\
\hline Kim et al. (2019) & LH:AH & 3100 & . & . & 3235 & . & . & & & & & $0.0 \%$ & $0.0 \%$ \\
\hline Kim et al. (2018) & LH:AH & 343 & . & . & 222 & . & - & & & & & $0.0 \%$ & $0.0 \%$ \\
\hline Kong et al. (2014) & LH:AH & 40 & 14.80 & 4.70 & 48 & 18.00 & 6.50 & & & -3.20 & {$[-5.55 ;-0.85]$} & $0.9 \%$ & $5.8 \%$ \\
\hline Laterza et al. (2016) & LH:AH & 82 & 4.51 & 2.47 & 68 & 8.36 & 1.91 & $\mp$ & & -3.85 & {$[-4.55 ;-3.15]$} & $10.2 \%$ & $11.5 \%$ \\
\hline Li et al. (2007) & $\mathrm{LH}: \mathrm{AH}$ & 90 & 13.81 & 8.33 & 35 & 13.69 & 6.65 & & & 0.12 & {$[-2.68 ; 2.92]$} & $0.6 \%$ & $4.7 \%$ \\
\hline Malzoni et al. (2009) & LH:AH & 65 & 4.15 & 0.85 & 62 & 6.92 & 1.08 & & & -2.77 & {$[-3.11 ;-2.44]$} & $43.7 \%$ & $12.5 \%$ \\
\hline Melamed et al. (2018) & LH:AH & 1225 & & . & 1236 & & - & & & & & $0.0 \%$ & $0.0 \%$ \\
\hline Mendivil et al. (2015) & $\mathrm{LH}: \mathrm{RH}: \mathrm{AH}$ & 49 & 2.95 & 2.30 & 39 & 5.04 & 3.02 & & & -2.09 & {$[-3.24 ;-0.94]$} & $3.8 \%$ & $9.9 \%$ \\
\hline Naik et al. (2010) & $\mathrm{LH}: \mathrm{AH}$ & 8 & 5.23 & 1.05 & 7 & 6.76 & 0.37 & $\mp$ & & -1.53 & {$[-2.30 ;-0.76]$} & $8.4 \%$ & $11.3 \%$ \\
\hline Nam et al. (2011) & $\mathrm{LH}: \mathrm{AH}$ & 263 & 13.28 & 7.79 & 263 & 21.49 & $12.75-$ & . & & -8.22 & {$[-10.02 ;-6.41]$} & $1.5 \%$ & $7.4 \%$ \\
\hline Obermair et al. (2020) & $\mathrm{LH}(+\mathrm{RH}): \mathrm{AH}$ & 279 & 4.83 & 12.66 & 257 & 6.73 & 12.25 & & & -1.90 & {$[-4.01 ; 0.21]$} & $1.1 \%$ & $6.4 \%$ \\
\hline Paik et al. (2019) & LH:AH & 119 & & . & 357 & & - & & & & & $0.0 \%$ & $0.0 \%$ \\
\hline Park et al. (2016) & LH:AH & 186 & 10.40 & . & 107 & 17.50 & - & 1 & & -7.10 & & $0.0 \%$ & $0.0 \%$ \\
\hline Ramirez et al. (2018) & $\mathrm{LH}(+\mathrm{RH}): \mathrm{AH}$ & 319 & 4.66 & 12.48 & 312 & 6.51 & 11.99 & 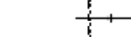 & & -1.85 & {$[-3.76 ; 0.06]$} & $1.4 \%$ & $7.1 \%$ \\
\hline Xiao et al. (2016) & LH:AH & 42 & - & - & 16 & - & - & & & & & $0.0 \%$ & $0.0 \%$ \\
\hline \multirow{3}{*}{\multicolumn{2}{|c|}{$\begin{array}{l}\text { Fixed effect model } \\
\text { Random effects model }\end{array}$}} & 7058 & & & 7701 & & & $\oint$ & & \multirow{3}{*}{$\begin{array}{l}-3.06 \\
-3.03\end{array}$} & {$[-3.28 ;-2.83]$} & $100.0 \%$ & $=$ \\
\hline & & & & & & & & $\dot{\phi}$ & & & {$[-3.79 ;-2.27]$} & -- & $100.0 \%$ \\
\hline & $p<0.01$ & & & & & & $\Gamma$ & & 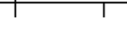 & & & & \\
\hline & & & & & & & -10 & -5 & 0 & 10 & & & \\
\hline
\end{tabular}

Fig. 8 Hospital stay LH vs AH

random effects model was used in the LH versus AH analysis and showed no significant difference (Fig. 22). RCT and retrospective design as well as the date of publication led to no different result.

LH versus RH and RH versus AH showed no significant difference in PM, respectively (Figs. 23, 24).

Subgroup analysis for study design and date of publications in the $\mathrm{LH}$ versus $\mathrm{RH}$ and $\mathrm{RH}$ versus $\mathrm{AH}$ groups could not be assessed due to the lack of studies in either one of the groups.

\section{Discussion}

In our meta-analysis of 27 studies, we evaluated the perioperative morbidities of minimally-invasive versus open hysterectomy in early cervical cancer.

LH was associated with lower blood loss and shorter hospital stay as well as equivalent postoperative morbidity compared to $\mathrm{AH}$ in the general analysis, even though operation time in the LH group was increased. Intraoperative morbidity was not only found to be lower in the retrospective studies, but also equivalent in the RCT studies and overall analysis. Remarkable in this case is the $95 \% \mathrm{CI}$ of the overall analysis revealing an upper benchmark only slightly above 1 (RR $0.9095 \%$ CI [0.80; 1.02]), almost also making the IM in general statistically significantly less in the LH group. There was another discordant result comparing only RCT to retrospective studies. The meta-analysis revealed no significant difference of EBL between $\mathrm{LH}$ and $\mathrm{AH}$ in the RCT group, but a significantly lower blood loss in the LH group of retrospective studies. In the overall analysis, also including retrospective designs, the lower blood loss in the LH group was statistically significant.

In the meta-analyses of Cao et al. [6] and Zhao et al. [7] comparing $\mathrm{LH}$ and $\mathrm{AH}$, the results of HS, EBL, IM, PM and OT were concurrent to our analysis. In contrast to our analysis, Zhao et al. included cases of patients receiving 
Subgroup

RCT

Campos et al. (2013)

Frumovitz et al. (2020)

Naik et al. (2010)

Obermair et al. (2020)

Ramirez et al. (2018)

Random effects model

$\chi_{2}^{2}=0.17(p=0.92)$

retrospective

Chiva et al. (2020)

Diver et al. (2016)

Dos Reis et al. (2018)

Kim et al. (2019)

Kim et al. (2018)

Kong et al. (2014)

Laterza et al. (2016)

Li et al. (2007)

Malzoni et al. (2009)

Melamed et al. (2018)

Mendivil et al. (2015)

Nam et al. (2011)

Paik et al. (2019)

Park et al. (2016)

Xiao et al. (2016)

Random effects model

$\chi_{7}^{2}=56.79(\rho<0.01)$

\section{Fixed effects (plural) model} $\chi_{1}^{2}=11.23(p<0.01)$

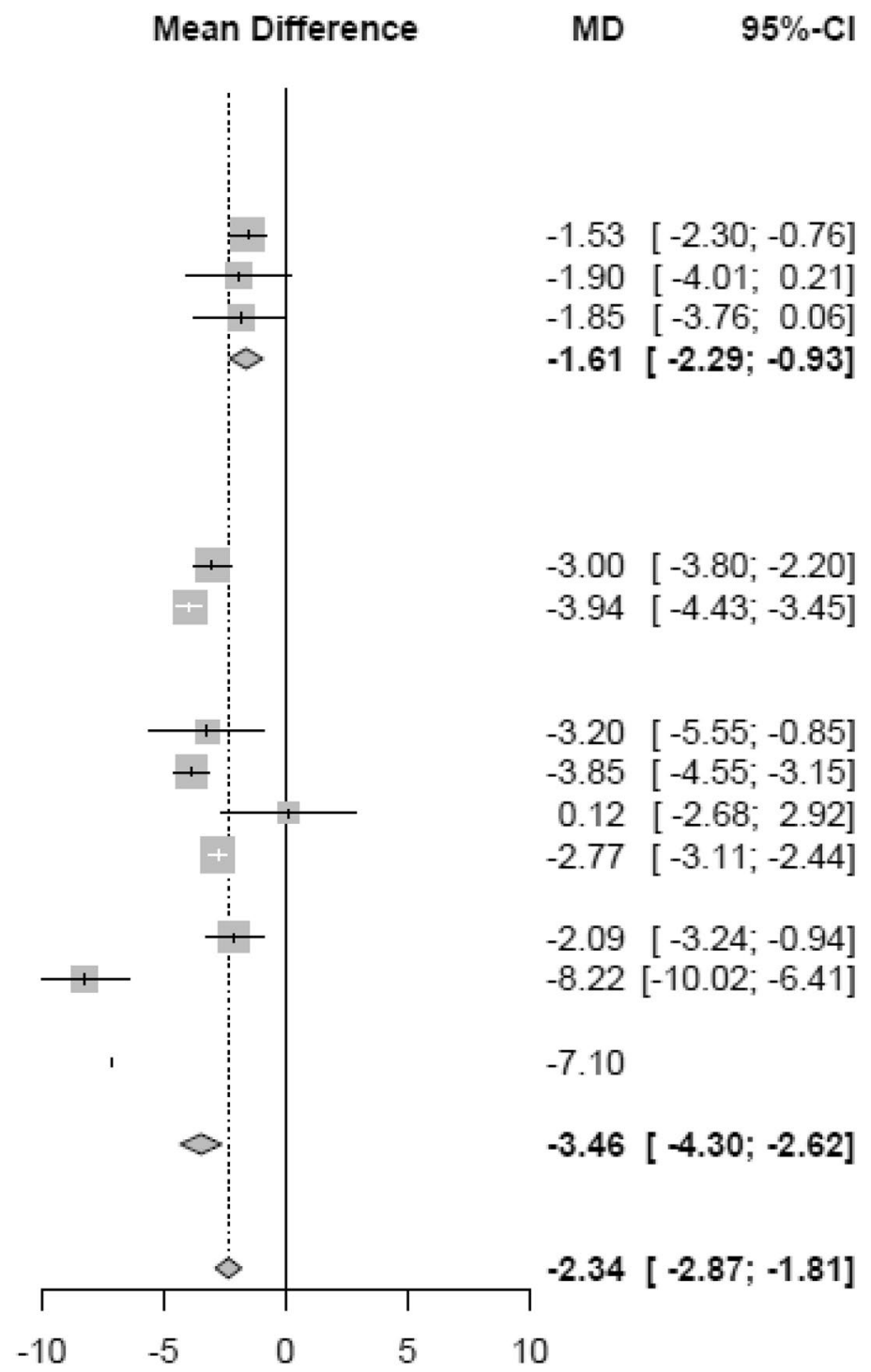

Fig. 9 Hospital stay LH vs AH (study design)

neoadjuvant chemotherapy, which could possibly lead to a bias by complicating the situs' condition.

RH showed lower blood loss and hospital stay, as well as equivalent postoperative morbidity compared to $\mathrm{AH}$. Intraoperative morbidity was lower than in $\mathrm{AH}$, whereas operation time was increased in RH. As well as in LH, the surgeon's learning curve and the high requirements of laparoscopic techniques could be a reason for the longer operation time than in the more established abdominal approach [18, 19]. Zhang et al. [12] and Park et al. [10] both published meta-analyses comparing $\mathrm{RH}$ to $\mathrm{LH}$ or $\mathrm{AH}$ confirming the safety and effectiveness of RH. All intra- and postoperative endpoints in RH were at least similar to AH, in EBL and HS even in favor of RH, which is concordant to our analysis.

In our analysis, there was no significant difference between LH and RH in any endpoint examined. In several aspects our results are comparable to those of previous meta-analyses but also show differences. Zhou et al. [11] compared RH and LH in their meta-analysis in 2016. Their findings such as less blood loss and shorter hospital stay in the RH group could not be reproduced in our analysis, however it needs to be considered that our search results included only four suitable studies. There is a possible bias in our analysis due to the small number of studies comparing $\mathrm{RH}$ to $\mathrm{LH}$.

Our review also has limitations, which mainly involve the heterogeneous and mostly retrospective study designs. Secondly, the smaller patient samples could lead to a bias dependent on the surgeon's abilities in the field of especially newer operative techniques, such as the robotic hysterectomy. Moreover, we did not distinguish between the different types of Piver classification or additional vaginal approach 
Subgroup

LACC

Frumovitz et al. (2020)

Obermair et al. (2020)

Ramirez et al. (2018)

Random effects model

$\chi_{1}^{2}=0(p=0.97)$

\section{post LACC}

Chiva et al. (2020)

Kim et al. (2018)

Paik et al. (2019)

Random effects model

not applicable

\section{pre LACC}

Campos et al. (2013)

Diver et al. (2016)

Dos Reis et al. (2018)

Kim et al. (2019)

Kong et al. (2014)

Laterza et al. (2016)

Li et al. (2007)

Malzoni et al. (2009)

Melamed et al. (2018)

Mendivil et al. (2015)

Naik et al. (2010)

Nam et al. (2011)

Park et al. (2016)

Xiao et al. (2016)

Random effects model

$\chi_{8}^{2}=73.8(p<0.01)$

\section{Fixed effects (plural) model} $\chi_{1}^{2}=2.55(p=0.11)$
Mean Difference

MD

$95 \%-\mathrm{Cl}$

$-1.90 \quad[-4.01 ; 0.21]$

$-1.85[-3.76 ; 0.06]$

$-1.87[-3.29 ;-0.46]$
$-3.00 \quad[-3.80 ;-2.20]$

$-3.94[-4.43 ;-3.45]$

$-3.20 \quad[-5.55 ;-0.85]$

$-3.85[-4.55 ;-3.15]$

$0.12 \quad[-2.68 ; 2.92]$

$-2.77 \quad[-3.11 ;-2.44]$

$-2.09 \quad[-3.24 ;-0.94]$

$-1.53[-2.30 ;-0.76]$

$-8.22[-10.02 ;-6.41]$

$-7.10$

$-3.21[-4.04 ;-2.38]$

$-2.87[-3.58 ;-2.16]$

$\begin{array}{lllll}-10 & -5 & 0 & 5 & 10\end{array}$

Fig. 10 Hospital stay LH vs AH (date of publication)

\begin{tabular}{|c|c|c|c|c|c|}
\hline \multirow[b]{2}{*}{ Study } & \multirow[b]{2}{*}{ cohort } & \multicolumn{2}{|c|}{ Experimental } & \multicolumn{2}{|r|}{ Control } \\
\hline & & Total & Mean SD & Total & Mean SD \\
\hline Corrado et al. (2014) & $\mathrm{LH}: \mathrm{RH}$ & 30 & 2.832 .21 & 30 & $3.36 \quad 1.23$ \\
\hline Mendivil et al. (2015) & LH:RH:AH & 49 & 2.952 .30 & 58 & 2.504 .54 \\
\hline Sert et al. (2007) & $\mathrm{LH}: \mathrm{RH}$ & 7 & 8.00 & 7 & 4.00 \\
\hline Tinelli et al. (2011) & LH:RH & 76 & 4.002 .00 & 23 & 3.001 .00 \\
\hline Vizzielli et al. (2016) & $\mathrm{LH}: \mathrm{RH}$ & 42 & 6.682 .53 & 21 & 3.860 .79 \\
\hline $\begin{array}{l}\text { Fixed effect model } \\
\text { Random effects model } \\
\text { Heterogeneity: } \tau^{2}=1.7297\end{array}$ & & 204 & & 139 & \\
\hline
\end{tabular}

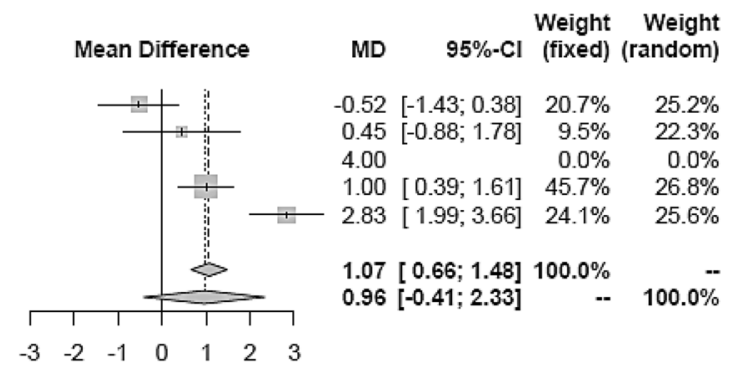

Fig. 11 Hospital stay LH vs RH 


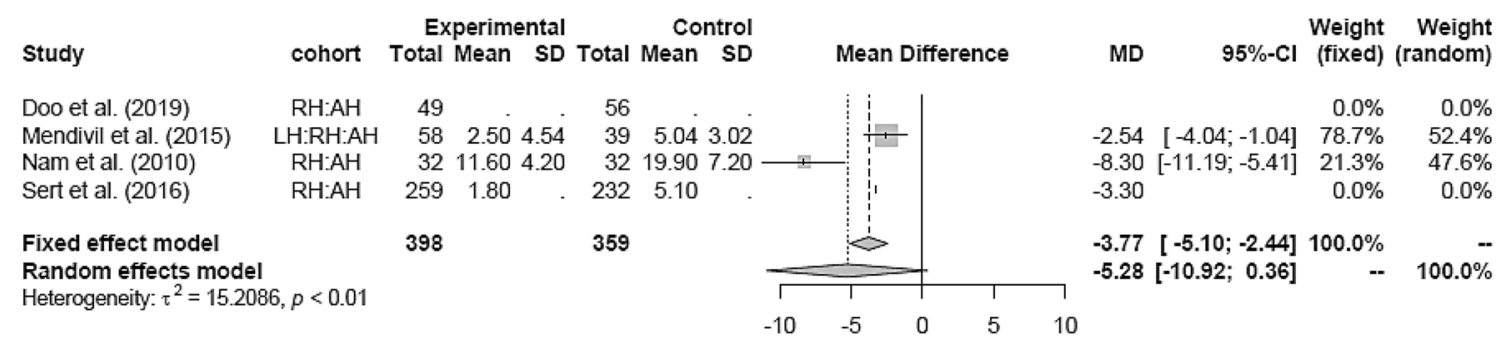

Fig. 12 Hospital stay $\mathrm{RH}$ vs $\mathrm{AH}$

\begin{tabular}{|c|c|c|c|c|c|c|c|}
\hline \multirow[b]{2}{*}{ Study } & \multirow[b]{2}{*}{ cohort } & \multicolumn{4}{|c|}{ Experimental } & \multicolumn{2}{|c|}{ Control } \\
\hline & & Total & Mean & SD & Total & Mean & SD \\
\hline Campos et al. (2013) & $\mathrm{LH}: \mathrm{AH}$ & 16 & 264.38 & 49.29 & 14 & 240.36 & 626.85 \\
\hline Chiva et al. (2020) & $\mathrm{LH}(+\mathrm{RH}): \mathrm{AH}$ & 291 & & & 402 & & \\
\hline Diver et al. (2016) & LH:AH & 101 & & & 282 & & \\
\hline Dos Reis et al. (2018) & LH:AH & 121 & 323.61 & 66.85 & 427 & 293.69 & 963.86 \\
\hline Frumovitz et al. (2020) & $\mathrm{LH}(+\mathrm{RH}): \mathrm{AH}$ & 319 & . & . & 312 & & . \\
\hline Kim et al. (2019) & $\mathrm{LH}: \mathrm{AH}$ & 3100 & & & 3235 & & \\
\hline Kim et al. (2018) & LH:AH & 343 & & & 222 & & \\
\hline Kong et al. (2014) & $\mathrm{LH}: \mathrm{AH}$ & 40 & 254.50 & 43.70 & 48 & 246.00 & 73.00 \\
\hline Laterza et al. (2016) & $\mathrm{LH}: \mathrm{AH}$ & 82 & & & 68 & & \\
\hline Li et al. (2007) & LH:AH & 90 & 262.99 & 967.60 & 35 & 217.20 & 71.56 \\
\hline Malzoni et al. (2009) & LH:AH & 65 & 198.23 & 312.38 & 62 & 159.43 & В 16.99 \\
\hline Melamed et al. (2018) & $\mathrm{LH}: \mathrm{AH}$ & 1225 & & & 1236 & & \\
\hline Mendivil et al. (2015) & LH:RH:AH & 49 & 106.80 & 12.88 & 39 & 143.40 & 24.32 \\
\hline Naik et al. (2010) & LH:AH & 8 & 187.08 & 3 17.08 & 7 & 133.54 & $4 \quad 6.41$ \\
\hline Nam et al. (2011) & LH:AH & 263 & 250.71 & 60.03 & 263 & 250.97 & 761.09 \\
\hline Obermair et al. (2020) & $\mathrm{LH}(+\mathrm{RH}): \mathrm{AH}$ & 279 & 218.35 & 64.56 & 257 & 190.29 & 964.63 \\
\hline Paik et al. (2019) & LH:AH & 119 & . & . & 357 & & . \\
\hline Park et al. (2016) & LH:AH & 186 & & . & 107 & & . \\
\hline Ramirez et al. (2018) & $\mathrm{LH}(+\mathrm{RH}): \mathrm{AH}$ & 319 & & & 312 & & . \\
\hline Xiao et al. (2016) & LH:AH & 42 & & - & 16 & & . \\
\hline $\begin{array}{l}\text { Fixed effect model } \\
\text { Random effects mode } \\
\text { Heterogeneity: } \tau^{2}=1084 .\end{array}$ & & 058 & & & 701 & & \\
\hline
\end{tabular}

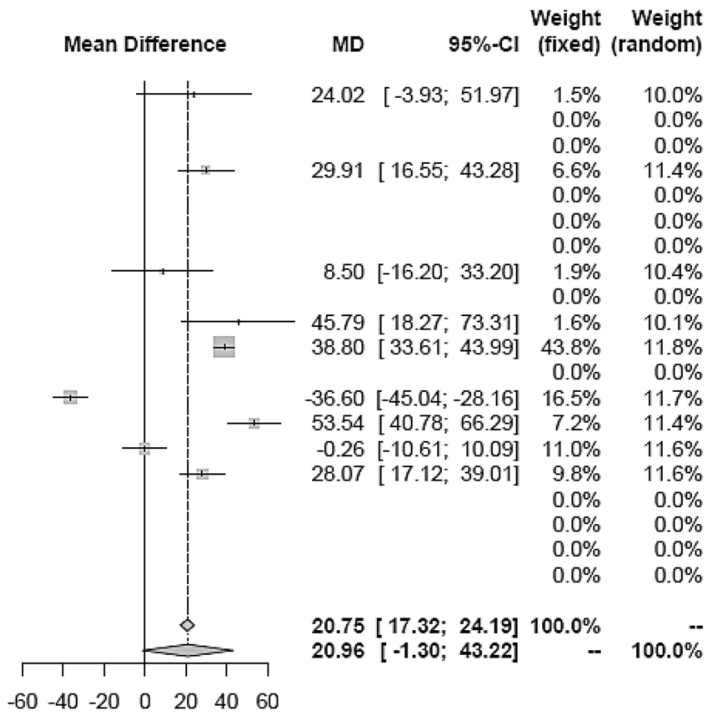

Fig. 13 Operation time $\mathrm{LH}$ vs $\mathrm{AH}$

(LAVH), which could bias the intraoperative complication rate. In addition, several studies combined $\mathrm{RH}$ and $\mathrm{LH}$ into an overall minimally invasive group, which led to a small number of studies showing results of comparing only $\mathrm{RH}$ to either LH or AH. A further limitation is the missing analysis of quality of life in the primary studies. Quality of life after surgical therapy is an important endpoint in need of improvement of evaluation. In the large randomized controlled trial of the LACC study [20], the quality of life were evaluated by standardized questionnaires after a median follow-up of three years. In this analysis, no differences between the abdominal and laparoscopic approaches were seen after 6 weeks and 3 months after surgery. The authors, therefore, conclude to prefer AH over LH due to improved oncologic outcome and equivalent morbidity. Long term results are pending at the time of manuscript editing.

This meta-analysis focuses on patients' morbidity. The oncologic outcome was analyzed by our research group [17] and showed a dependency of oncologic outcome the surgical approach using various protective measures (no use of uterine manipulator, colpotomy) against tumor spillage. This analysis supports the possible improvement of oncologic safety in minimally-invasive approaches by adapting surgical techniques and was recently supported by the result of a systematic review comparing incidence, mortality and centralization of treatment in early-stage cervical cancer in seven Asian countries. In their review, Hiroko et al. showed that minimally invasive surgery without a uterine manipulator or making a vaginal cuff closure produced similar recurrence rates compared with open surgery (MIS without uterine manipulator vs open-surgery: $10.5 \%$ vs $10.1 \%$, and MIS with cuff closure vs open-surgery $7.2 \%$ vs $10.1 \%$; all $P>0.05$ ) [21]. In addition, the dependence of oncologic outcome on the treatment center was shown in a current cohort analysis [22]. Patients treated in university cancer centers revealed higher survival rates compared to non-university cancer centers, independently from the surgical approach (recurrence-free survival HR $0.49,95 \%$ CI $0.28-0.83 ; p=0.009$ and overall survival HR 0.5 , 95\% CI $2.06-0.94 ; p=0.031$ ). However, an analysis in the subgroups applied in our previous study could not be performed in this analysis due to a lack of data in respect to perioperative morbidities.

A meta-analysis of randomized-controlled studies [23] examining the outcome of early-stage endometrial cancer 
Subgroup

RCT

Campos et al. (2013)

Frumovitz et al. (2020)

Naik et al. (2010)

Obermair et al. (2020)

Ramirez et al. (2018)

Random effects model

$\chi_{2}^{2}=9.82(p<0.01)$

retrospective

Chiva et al. (2020)

Diver et al. (2016)

Dos Reis et al. (2018)

Kim et al. (2019)

Kim et al. (2018)

Kong et al. (2014)

Laterza et al. (2016)

Li et al. (2007)

Malzoni et al. (2009)

Melamed et al. (2018)

Mendivil et al. (2015)

Nam et al. (2011)

Paik et al. (2019)

Park et al. (2016)

Xiao et al. (2016)

Random effects model

$\chi_{5}^{2}=241.51(p<0.01)$

Fixed effects (plural) model $\chi_{1}^{2}=1.51(p=0.22)$



Fig. 14 Operation time LH vs AH (study design)

patients treated with either LH or AH showed reduced BL, shorter HS, lower PM in the LH group and no difference in IM. When comparing these results to the findings of our analysis, they differ from ours only in case of PM, which showed no significant difference in our analysis but was significantly lower in LH for endometrial cancer ( $R R=0.58,95 \%$ CI 0.37-0.91). Furthermore, no difference in OS and DFS was shown between the $\mathrm{LH}$ and $\mathrm{AH}$ group of endometrial cancer. Therefore, $\mathrm{LH}$ can be considered a safe procedure to treat early-stage endometrial cancer concerning morbidity and oncologic mortality [24].

This meta-analysis and systematic review showed that LH and RH are safe surgical approaches concerning periand postoperative morbidities.

\section{Conclusion}

Our meta-analysis showed no significant difference between RH and LH concerning perioperative complications. Operation time was longer in both $\mathrm{RH}$ and $\mathrm{LH}$ than in $\mathrm{AH}$, but did not lead to a rise in intraoperative complications. Concerning intra- and postoperative morbidity, minimally invasive approaches seem to be superior to open hysterectomy but RCT subgroup analysis did not reveal a difference. Further randomized controlled studies are pending.

Author contribution $\mathrm{KJ}$ : data collection and management, manuscript writing and editing. GE: data collection. SP: data analysis. FT: data analysis. JM: manuscript editing. KR: manuscript editing. $\mathrm{HH}$ : 
Subgroup

LACC

Frumovitz et al. (2020)

Obermair et al. (2020)

Ramirez et al. (2018)

Random effects model

not applicable

post LACC

Chiva et al. (2020)

Kim et al. (2018)

Paik et al. (2019)

Random effects model

not applicable

pre LACC

Campos et al. (2013)

Diver et al. (2016)

Dos Reis et al. (2018)

Kim et al. (2019)

Kong et al. (2014)

Laterza et al. (2016)

Li et al. (2007)

Malzoni et al. (2009)

Melamed et al. (2018)

Mendivil et al. (2015)

Naik et al. (2010)

Nam et al. (2011)

Park et al. (2016)

Xiao et al. (2016)

Random effects model

$x_{7}^{2}=270.71(p<0.01)$

Fixed effects (plural) model $\chi_{1}^{2}=0.32(p=0.57)$
Mean Difference

MD

$95 \%-\mathrm{Cl}$

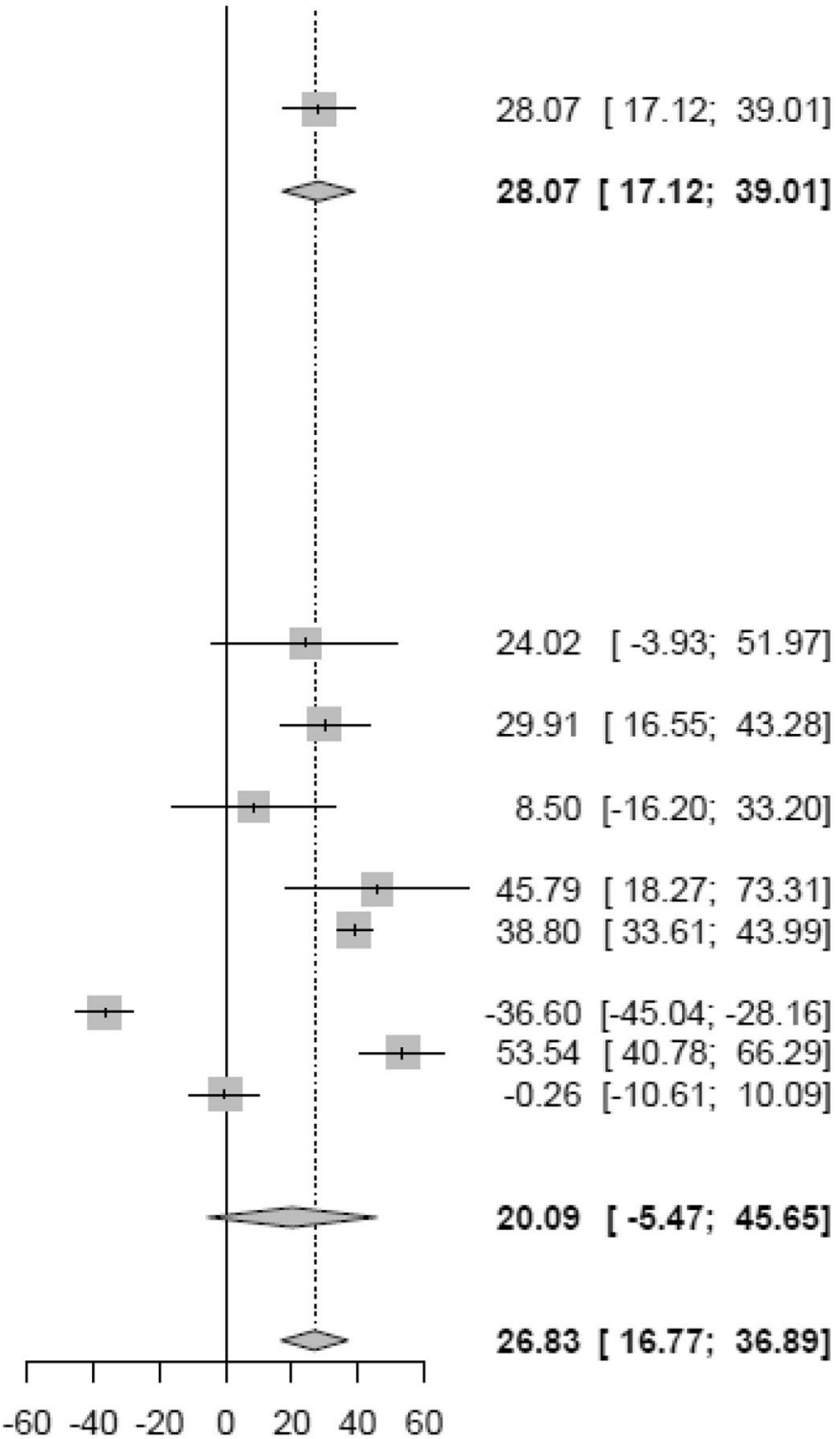

Fig. 15 Operation time $\mathrm{LH}$ vs $\mathrm{AH}$ (date of publication)

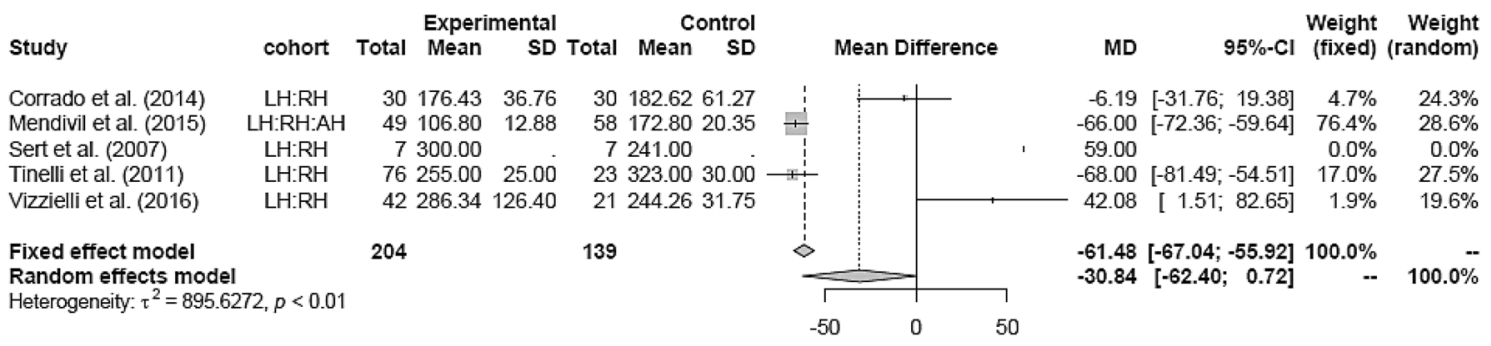

Fig. 16 Operation time LH vs RH 


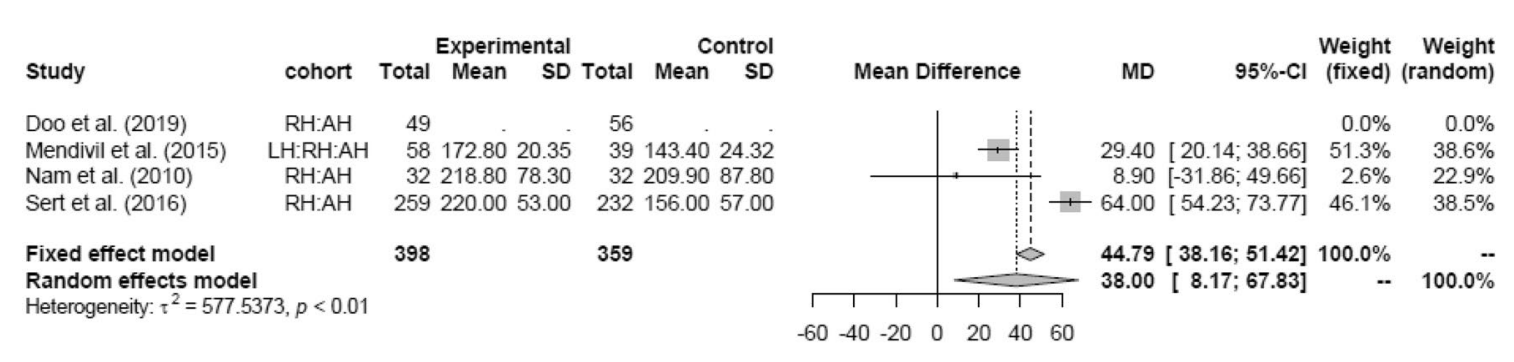

Fig. 17 Operation time $\mathrm{RH}$ vs $\mathrm{AH}$

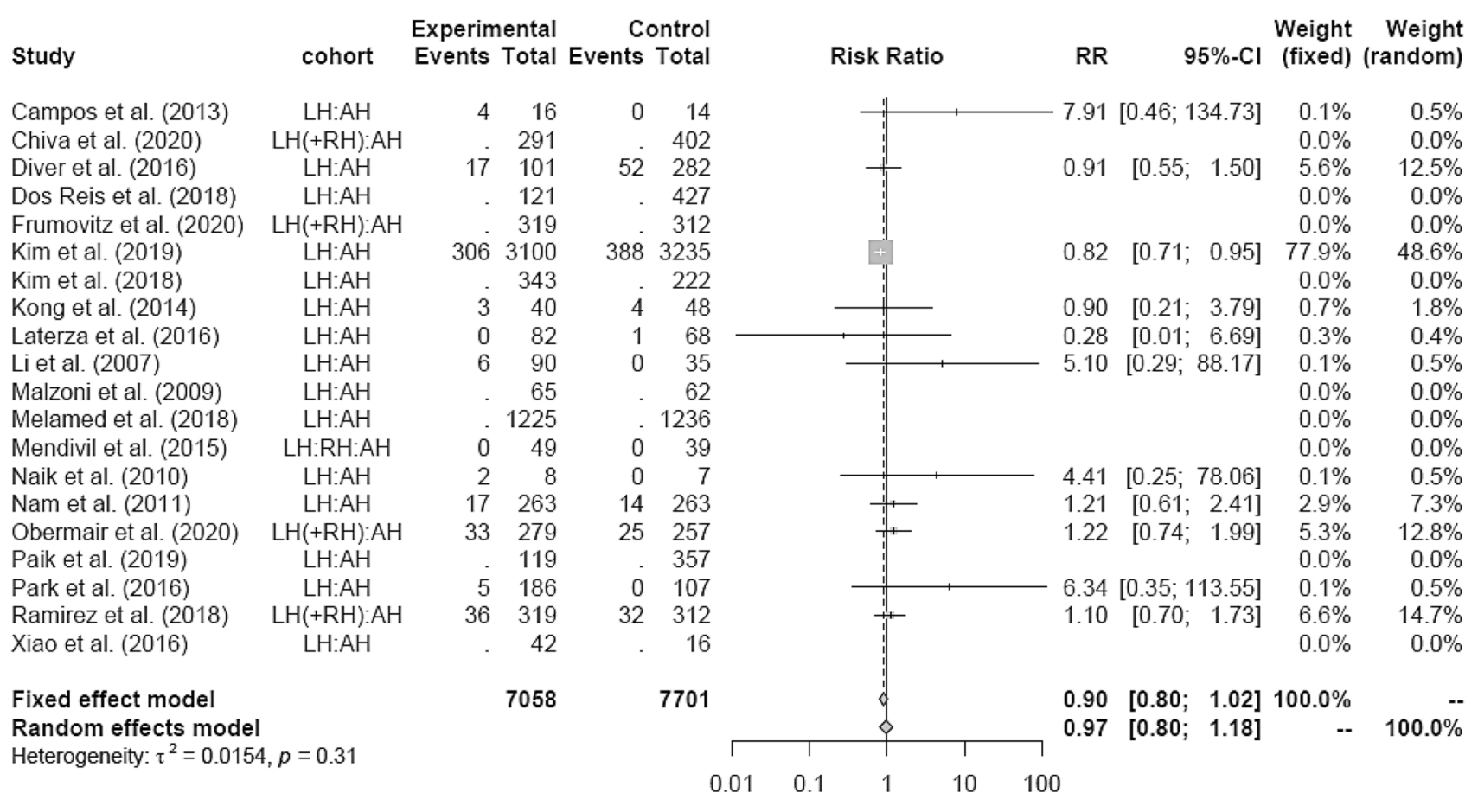

Fig. 18 Intraoperative morbidity $\mathrm{LH}$ vs $\mathrm{AH}$

project development. HP: project development, supervision, manuscript editing.

Funding Open Access funding enabled and organized by Projekt DEAL. The study did not receive funding.

\section{Declarations}

Conflict of interest All authors declare no conflict of interest.
Research involving human participants and/or animals This study does not contain any studies with human participants or animals performed by any of the authors.

Open Access This article is licensed under a Creative Commons Attribution 4.0 International License, which permits use, sharing, adaptation, distribution and reproduction in any medium or format, as long as you give appropriate credit to the original author(s) and the source, provide a link to the Creative Commons licence, and indicate if changes were made. The images or other third party material in this article are included in the article's Creative Commons licence, unless indicated otherwise in a credit line to the material. If material is not included in 
Subgroup

RCT

Campos et al. (2013)

Frumovitz et al. (2020)

Naik et al. (2010)

Obermair et al. (2020)

Ramirez et al. (2018)

Random effects model

$\chi_{3}^{2}=2.67(p=0.45)$

retrospective

Chiva et al. (2020)

Diver et al. (2016)

Dos Reis et al. (2018)

Kim et al. (2019)

Kim et al. (2018)

Kong et al. (2014)

Laterza et al. (2016)

Li et al. (2007)

Malzoni et al. (2009)

Melamed et al. (2018)

Mendivil et al. (2015)

Nam et al. (2011)

Paik et al. (2019)

Park et al. (2016)

Xiao et al. (2016)

Random effects model

$\chi_{6}^{2}=5.2(p=0.52)$

Fixed effects (plural) model $\chi_{1}^{2}=3.77(p=0.05)$
Risk Ratio

RR

$95 \%-\mathrm{Cl}$



Fig. 19 Intraoperative morbidity LH vs AH (study design)

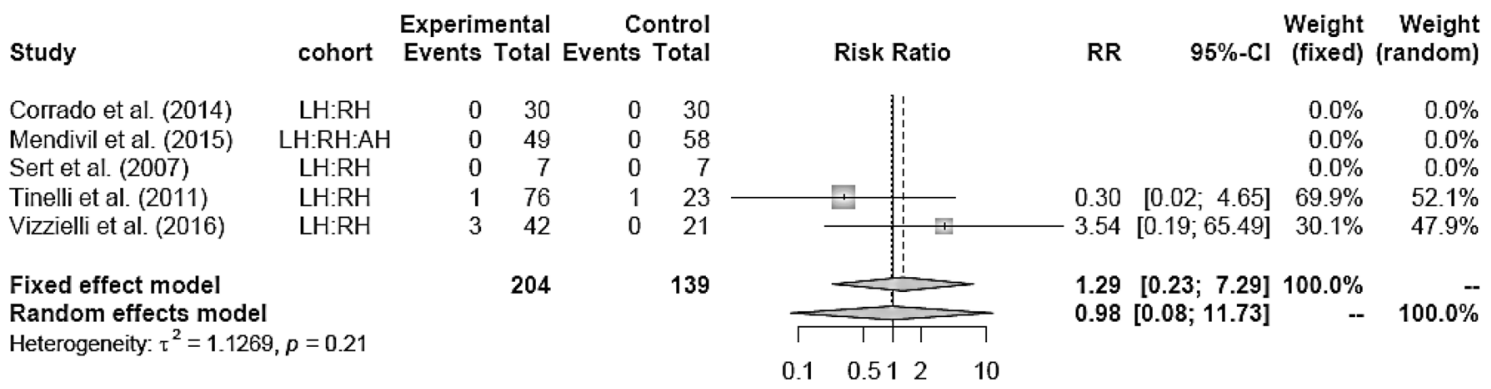

Fig. 20 Intraoperative morbidity LH vs RH 




Fig. 21 Intraoperative morbidity $\mathrm{RH}$ vs $\mathrm{AH}$

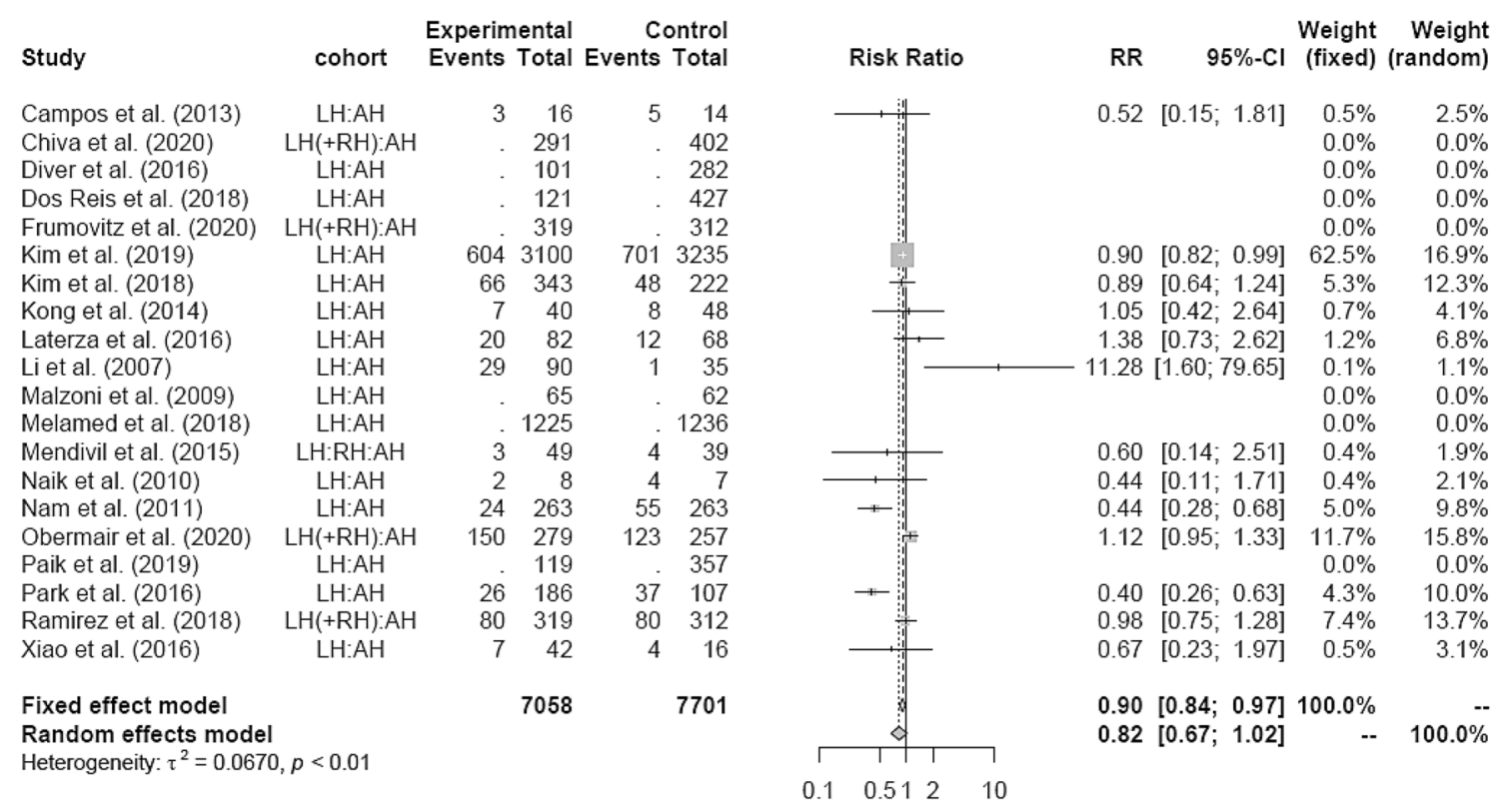

Fig. 22 Postoperative morbidity LH vs AH

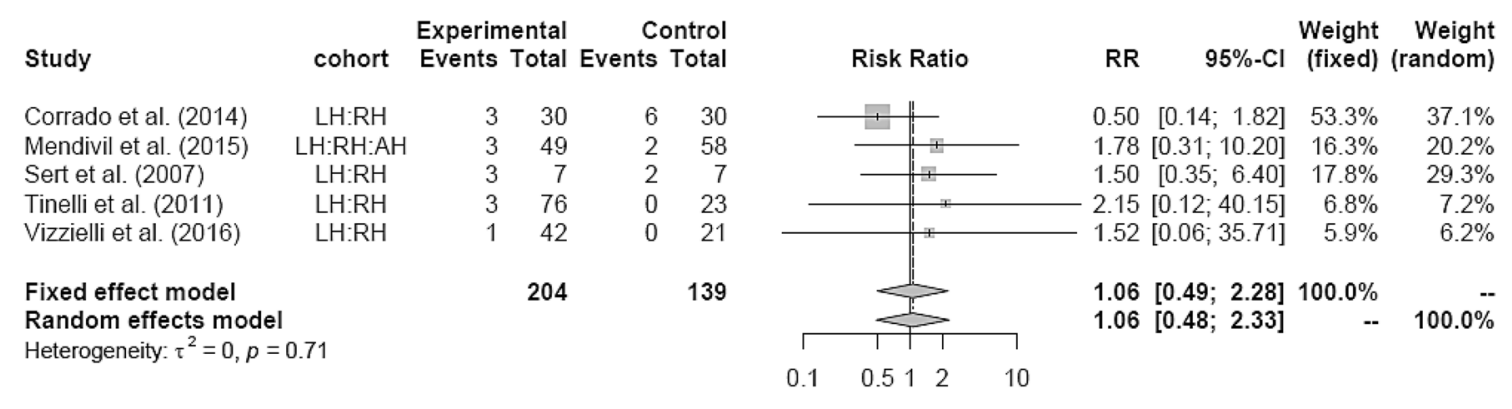

Fig. 23 Postoperative morbidity LH vs RH

the article's Creative Commons licence and your intended use is not permitted by statutory regulation or exceeds the permitted use, you will need to obtain permission directly from the copyright holder. To view a copy of this licence, visit http://creativecommons.org/licenses/by/4.0/.

\section{References}

1. AWMF. S3-Leitlinie Diagnostik, Therapie und Nachsorge der Patientin mit Zervixkarzinom. https://www.awmf.org/uploads/ tx_szleitlinien/032-0. 




Fig. 24 Postoperative morbidity $\mathrm{RH}$ vs $\mathrm{AH}$

2. Nam J-H, Park J-Y, Kim D-Y, Kim J-H, Kim Y-M, Kim Y-T (2012) Laparoscopic versus open radical hysterectomy in earlystage cervical cancer: long-term survival outcomes in a matched cohort study. Ann Oncol [Internet]. 23(4):903-11. Available at https://linkinghub.elsevier.com/retrieve/pii/S09237534193465 4X

3. Roy M, Plante M, Renaud M-C (2005) Laparoscopically assisted vaginal radical hysterectomy. Best Pract Res Clin Obstet Gynaecol. 19(3 SPEC):377-86

4. Malzoni M, Tinelli R, Cosentino F, Fusco A, Malzoni C (2009) Total laparoscopic radical hysterectomy versus abdominal radical hysterectomy with lymphadenectomy in patients with early cervical cancer: our experience. Ann Surg Oncol [Internet]. 16(5):1316-23. Available at http://link.springer.com/10.1245/ s10434-009-0342-7

5. Wang Y, Deng L, Xu H, Zhang Y, Liang Z (2015) Laparoscopy versus laparotomy for the management of early stage cervical cancer. BMC Cancer [Internet]. 15:928. Available at http:// www.ncbi.nlm.nih.gov/pubmed/26596955

6. Cao T, Feng Y, Huang Q, Wan T, Liu J (2015) Prognostic and safety roles in laparoscopic versus abdominal radical hysterectomy in cervical cancer: a meta-analysis. J Laparoendosc Adv Surg Tech [Internet]. 25(12):990-998. Available at http://www. liebertpub.com/doi/10.1089/lap.2015.0390

7. Zhao Y, Hang B, Xiong G-W, Zhang X-W (2017) Laparoscopic radical hysterectomy in early stage cervical cancer: a systematic review and meta-analysis. J Laparoendosc Adv Surg Tech [Internet]. 27(11):1132-44. Available at http://www.liebertpub. com/doi/10.1089/lap.2017.0022

8. Ramirez PT, Frumovitz M, Pareja R, Lopez A, Vieira M, Ribeiro R, et al (2018) Minimally invasive versus abdominal radical hysterectomy for cervical cancer. N Engl J Med [Internet]. 379(20):1895-904. Available from: http://www.nejm.org/ doi/10.1056/NEJMoa1806395

9. Holloway RW, Patel SD, Ahmad S (2009) Robotic surgery in gynecology. Scand J Surg [Internet] 98(2):96-109. Available at http://journals.sagepub.com/doi/10.1177/145749690909800205

10. Park DA, Yun JE, Kim SW, Lee SH (2017) Surgical and clinical safety and effectiveness of robot-assisted laparoscopic hysterectomy compared to conventional laparoscopy and laparotomy for cervical cancer: A systematic review and meta-analysis. Eur J Surg Oncol [Internet]. 43(6):994-1002. Available at https:// linkinghub.elsevier.com/retrieve/pii/S0748798316306874

11. Zhou J, Xiong BH, Ma L, Cheng Y, Huang W, Zhao L (2016) Robotic vs laparoscopic radical hysterectomy for cervical cancer: a meta-analysis. Int J Med Robot Comput Assist Surg [Internet]. 12(1):145-54. Available at http://doi.wiley.com/10. $1002 /$ rcs. 1652

12. Zhang S, Ding T, Cui Z, Lv Y, Jiang R (2019) Efficacy of robotic radical hysterectomy for cervical cancer compared with that of open and laparoscopic surgery. Med (Baltim) [Internet]. 98(4):e14171. Available at http://journals.lww.com/00005792201901250-00032

13. Moher D (2009) Preferred reporting items for systematic reviews and meta-analyses: the PRISMA Statement. Ann Intern Med [Internet]. 151(4):264. Available at http://annals.org/article.aspx? doi=10.7326/0003-4819-151-4-200908180-00135

14. Sterne JAC, Savović J, Page MJ, Elbers RG, Blencowe NS, Boutron I, et al. (2019) RoB 2: a revised tool for assessing risk of bias in randomised trials. BMJ [Internet]. 366:14898. Available at http://www.ncbi.nlm.nih.gov/pubmed/31462531

15. Hardy RJ, Thompson SG (1996) A likelihood approach to metaanalysis with random effects. Stat Med [Internet]. 15(6):619-29. Available at: https://onlinelibrary.wiley.com/doi/10.1002/(SICI) 1097-0258(19960330) 15:6\%3C619::AID-SIM188\%3E3.0. CO;2-A

16. Mendivil AA, Rettenmaier MA, Abaid LN, Brown J V., Micha JP, Lopez KL, et al. (2016) Survival rate comparisons amongst cervical cancer patients treated with an open, robotic-assisted or laparoscopic radical hysterectomy: a five year experience. Surg Oncol [Internet]. 25(1):66-71. Available at https://linkinghub. elsevier.com/retrieve/pii/S0960740415300268

17. Kampers J, Gerhardt E, Sibbertsen P, Flock T, Klapdor R, Hertel $\mathrm{H}$, et al. (2021) Protective operative techniques in radical hysterectomy in early cervical carcinoma and their influence on diseasefree and overall survival: a systematic review and meta-analysis of risk groups. Arch Gynecol Obstet [Internet]. Available at https:// link.springer.com/10.1007/s00404-021-06082-y

18. Togami S, Kawamura T, Fukuda M, Yanazume S, Kamio M, Kobayashi H (2019) Learning curve and surgical outcomes for laparoscopic surgery, including pelvic lymphadenectomy, for early stage endometrial cancer. Jpn J Clin Oncol [Internet]. 49(6):5214. Available at http://www.ncbi.nlm.nih.gov/pubmed/30855684

19. Terzi H, Biler A, Demirtas O, Guler OT, Peker N, Kale A. (2016) Total laparoscopic hysterectomy: analysis of the surgical learning curve in benign conditions. Int J Surg [Internet]. 35:51-7. Available at http://www.ncbi.nlm.nih.gov/pubmed/27633451

20. Frumovitz M, Obermair A, Coleman RL, Pareja R, Lopez A, Ribero R, et al. (2020) Quality of life in patients with cervical cancer after open versus minimally invasive radical hysterectomy (LACC): a secondary outcome of a multicentre, randomised, open-label, phase 3, non-inferiority trial. Lancet Oncol [Internet]. 21(6):851-60. Available at https://linkinghub.elsevier.com/retri eve/pii/S1470204520300814

21. Hiroko M (2021) Surgical approach in early stage cervical cancer: the Asian view point. Eur J Gynaecol Oncol [Internet]. 42(1):30. Available at https://ejgo.imrpress.com/EN/10.31083/j.ejgo.2021. 01.2270

22. Gennari P, Gerken M, Mészáros J, Klinkhammer-Schalke M, Ortmann O, Eggemann H, et al. (2021) Minimal-invasive or open approach for surgery of early cervical cancer: the treatment center matters. Arch Gynecol Obstet [Internet]. https://doi.org/10. 
1055/s-0040-1718136. Available at http://www.thieme-connect. de/

23. Galaal K, Bryant A, Fisher AD, Al-Khaduri M, Kew F, Lopes AD (2012) Laparoscopy versus laparotomy for the management of early stage endometrial cancer. Cochrane Database Syst Rev [Internet]. 12(9):CD006655. Available at http://www.ncbi.nlm. nih.gov/pubmed/22972096

24. Colombo N, Creutzberg C, Amant F, Bosse T, González-Martín A, Ledermann J, et al. (2016) ESMO-ESGO-ESTRO consensus conference on endometrial cancer: diagnosis, treatment and follow-up. Int J Gynecol Cancer [Internet]. 26(1):2-30. Available at http://www.ncbi.nlm.nih.gov/pubmed/26645990

25. Campos L, Francisco Limberger L, Tetelbom Stein A, Nocchi KA (2013) Postoperative pain and perioperative outcomes after laparoscopic radical hysterectomy and abdominal radical hysterectomy in patients with early cervical cancer: a randomised controlled trial. Trials 14(1):293. https://doi.org/10.1186/1745-6215-14-293

26. Bogani G, Ghezzi F, Chiva L et al (2020) Patterns of recurrence after laparoscopic versus open abdominal radical hysterectomy in patients with cervical cancer: a propensity-matched analysis. Int J Gynecol Cancer 30(7):987-992. https://doi.org/10.1136/ ijgc-2020-001381

27. Corrado G, Fanfani F, Ghezzi F et al (2015) Mini-laparoscopic versus robotic radical hysterectomy plus systematic pelvic lymphadenectomy in early cervical cancer patients. A multi-institutional study. Eur J Surg Oncol. 41(1):136-141. https://doi.org/10. 1016/j.ejso.2014.10.048

28. Diver E, Hinchcliff E, Gockley A et al (2017) Minimally invasive radical hysterectomy for cervical cancer is associated with reduced morbidity and similar survival outcomes compared with laparotomy. J Minim Invasive Gynecol 24(3):402-406. https://doi. org/10.1016/j.jmig.2016.12.005

29. Doo DW, Kirkland CT, Griswold LH et al (2019) Comparative outcomes between robotic and abdominal radical hysterectomy for IB1 cervical cancer: results from a single high volume institution. Gynecol Oncol 153(2):242-247. https://doi.org/10.1016/j.ygyno. 2019.03.001

30. dos Reis R, Andrade CEMC, Frumovitz M, Munsell M, Ramirez PT (2018) Radical hysterectomy and age: outcomes comparison based on a minimally invasive vs an open approach. J Minim Invasive Gynecol 25(7):1224-1230. https://doi.org/10.1016/j. jmig.2018.03.002

31. Frumovitz M, Obermair A, Coleman RL et al (2020) Quality of life in patients with cervical cancer after open versus minimally invasive radical hysterectomy (LACC): a secondary outcome of a multicentre, randomised, open-label, phase 3, non-inferiority trial. Lancet Oncol 21(6):851-860. https://doi.org/10.1016/S14702045(20)30081-4

32. Kim SI, Lee M, Lee S et al (2019) Impact of laparoscopic radical hysterectomy on survival outcome in patients with FIGO stage IB cervical cancer: a matching study of two institutional hospitals in Korea. Gynecol Oncol 155(1):75-82. https://doi.org/10.1016/j. ygyno.2019.07.019

33. Kim JH, Kim K, Park SJ et al (2019) Comparative effectiveness of abdominal versus laparoscopic radical hysterectomy for cervical cancer in the Postdissemination Era. Cancer Res Treat 51(2):788796. https://doi.org/10.4143/crt.2018.120

34. Kong TW, Chang S-J, Lee J, Paek J, Ryu H-S (2014) Comparison of laparoscopic versus abdominal radical hysterectomy for FIGO Stage IB and IIA cervical cancer with tumor diameter of $3 \mathrm{~cm}$ or greater. Int J Gynecol Cancer 24(2):280-288. https://doi.org/10. 1097/IGC.0000000000000052

35. Laterza RM, Uccella S, Casarin J et al (2016) Recurrence of early stage cervical cancer after laparoscopic versus open radical surgery. Int J Gynecol Cancer 26(3):547-552. https://doi.org/10. 1097/IGC.0000000000000627
36. Li G, Yan X, Shang H, Wang G, Chen L, Han Y (2007) A comparison of laparoscopic radical hysterectomy and pelvic lymphadenectomy and laparotomy in the treatment of Ib-IIa cervical cancer. Gynecol Oncol 105(1):176-180. https://doi.org/10.1016/j. ygyno.2006.11.011

37. Malzoni M, Tinelli R, Cosentino F, Fusco A, Malzoni C (2009) Total laparoscopic radical hysterectomy versus abdominal radical hysterectomy with lymphadenectomy in patients with early cervical cancer: our experience. Ann Surg Oncol 16(5):1316-1323. https://doi.org/10.1245/s10434-009-0342-7

38. Melamed A, Margul DJ, Chen L et al (2018) Survival after minimally invasive radical hysterectomy for early-stage cervical cancer. N Engl J Med 379(20):1905-1914. https://doi.org/10.1056/ NEJMoa1804923

39. Mendivil AA, Rettenmaier MA, Abaid LN et al (2016) Survival rate comparisons amongst cervical cancer patients treated with an open, robotic-assisted or laparoscopic radical hysterectomy: a five year experience. Surg Oncol 25(1):66-71. https://doi.org/10. 1016/j.suronc.2015.09.004

40. Naik R, Jackson K, Lopes A, Cross P, Henry J (2010) Laparoscopic assisted radical vaginal hysterectomy versus radical abdominal hysterectomy-a randomised phase II trial: perioperative outcomes and surgicopathological measurements. BJOG An Int J Obstet Gynaecol 117(6):746-751. https://doi.org/10.1111/j. 1471-0528.2010.02479.x

41. Nam J-H, Park J-Y, Kim D-Y, Kim J-H, Kim Y-M, Kim Y-T (2012) Laparoscopic versus open radical hysterectomy in early-stage cervical cancer: long-term survival outcomes in a matched cohort study. Ann Oncol 23(4):903-911. https://doi.org/10.1093/annonc/ $\mathrm{mdr} 360$

42. Nam EJ, Kim SW, Kim S et al (2010) A case-control study of robotic radical hysterectomy and pelvic lymphadenectomy using 3 robotic arms compared with abdominal radical hysterectomy in cervical cancer. Int J Gynecol Cancer 20(7):1284-1289. https:// doi.org/10.1111/IGC.0b013e3181ef0a14

43. Obermair A, Asher R, Pareja R et al (2020) Incidence of adverse events in minimally invasive vs open radical hysterectomy in early cervical cancer: results of a randomized controlled trial. Am J Obstet Gynecol 222(3):249.e1-249.e10. https://doi.org/10.1016/j. ajog.2019.09.036

44. Paik ES, Lim MC, Kim M-H et al (2019) Comparison of laparoscopic and abdominal radical hysterectomy in early stage cervical cancer patients without adjuvant treatment: ancillary analysis of a Korean Gynecologic Oncology Group Study (KGOG 1028). Gynecol Oncol 154(3):547-553. https://doi.org/10.1016/j.ygyno. 2019.06.023

45. Park J-Y, Kim D, Suh D-S et al (2016) The role of laparoscopic radical hysterectomy in early-stage adenocarcinoma of the uterine cervix. Ann Surg Oncol 23(S5):825-833. https://doi.org/10.1245/ s10434-016-5489-4

46. Ramirez PT, Frumovitz M, Pareja R et al (2018) Minimally invasive versus abdominal radical hysterectomy for cervical cancer. $\mathrm{N}$ Engl J Med 379(20):1895-1904. https://doi.org/10.1056/NEJMo a1806395

47. Sert B, Abeler V (2007) Robotic radical hysterectomy in earlystage cervical carcinoma patients, comparing results with total laparoscopic radical hysterectomy cases. The future is now? Int J Med Robot Comput Assist Surg. 3(3):224-228. https://doi.org/ $10.1002 /$ rcs. 152

48. Sert BM, Boggess JF, Ahmad S et al (2016) Robot-assisted versus open radical hysterectomy: a multi-institutional experience for early-stage cervical cancer. Eur J Surg Oncol 42(4):513-522. https://doi.org/10.1016/j.ejso.2015.12.014

49. Tinelli R, Malzoni M, Cosentino F et al (2011) Robotics versus laparoscopic radical hysterectomy with lymphadenectomy in patients with early cervical cancer: a multicenter study. 
Ann Surg Oncol 18(9):2622-2628. https://doi.org/10.1245/ s10434-011-1611-9

50. Vizzielli G, Lucidi A, Gallotta V et al (2016) Robotic total mesometrial resection versus laparoscopic total mesometrial resection in early cervical cancer: a case-control study. J Minim Invasive Gynecol 23(5):804-809. https://doi.org/10.1016/j.jmig.2016.04. 006

51. Xiao M, Gao H, Bai H, Zhang Z (2016) Quality of life and sexuality in disease-free survivors of cervical cancer after radical hysterectomy alone. Med (Baltim) 95(36):e4787. https://doi.org/ 10.1097/MD.0000000000004787

Publisher's Note Springer Nature remains neutral with regard to jurisdictional claims in published maps and institutional affiliations. 